\section{Antenatal diagnosis of congenital heart disease by 3D ultrasonography using spatiotemporal image correlation with HDlive Flow and HDlive Flow silhouette rendering modes}

André Souza Malho ${ }^{1,2}$, Nathalie Jeanne Bravo-Valenzuela ${ }^{3}$, Renato Ximenes ${ }^{1}$, Alberto Borges Peixoto ${ }^{4,5}$, Edward Araujo Júnior ${ }^{6,7}$

${ }^{1}$ Latin American Fetal Medicine Foundation (FMF-LA), Campinas; ${ }^{2}$ Sector of Fetal Medicine, Santa Joana Hospital and Maternity, São Paulo; ${ }^{3}$ Discipline of Pediatrics, Department of Internal Medicine, Federal University of Rio de Janeiro (UFRJ), Rio de Janeiro; ${ }^{4}$ Mário Palmério University Hospital, University of Uberaba (UNIUBE), Uberaba; ${ }^{5}$ Department of Obstetrics and Gynecology, Federal University of Triângulo Mineiro (UFTM), Uberaba; ${ }^{6}$ Department of Obstetrics, Paulista School of Medicine - Federal University of São Paulo (EPM-UNIFESP), São Paulo; ${ }^{7}$ Medical Course, Municipal University of São Caetano do Sul (USCS), Bela Vista Campus, São Paulo, Brazil

This pictorial review describes the assessment of a great variety of types of congenital heart disease by three-dimensional ultrasonography with spatiotemporal image correlation using HDlive and the HDlive Flow silhouette rendering mode. These technologies provide fetal heart surface patterns by using a fixed virtual light source that propagates into the tissues, permitting a detailed reconstruction of the heart structures. In this scenario, ultrasound operators can freely select a better light source position to enhance the anatomical details of the fetal heart. HDlive and the HDlive Flow silhouette rendering mode improve depth perception and the resolution of anatomic cardiac details and blood vessel walls compared to standard two-dimensional ultrasonography.

Keywords: Fetal heart; Congenital heart disease; Three-dimensional ultrasound;

Spatiotemporal image correlation; HDlive

Key points: HDlive and the HDlive Flow silhouette rendering mode improve depth perception and the resolution of anatomic cardiac details and blood vessel walls. HDlive enables reconstruction of the fetal heart structures in realistic views starting from cardiac ultrasound views.
ULTRA

SONO

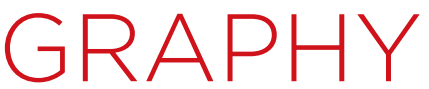

PICTORIAL ESSAY

https://doi.org/10.14366/usg.21165 pISSN: 2288-5919 • elSSN: 2288-5943 Ultrasonography 2022;41:578-596

Received: August 6, 2021

Revised: December 27, 2021

Accepted: January 14, 2022

Correspondence to:

Edward Araujo Júnior, PhD, Department of Obstetrics, Paulista School of Medicine - Federal University of São Paulo (EPM-UNIFESP), Rua Belchior de Azevedo, 156 apto. 111 Torre Vitoria, São Paulo, SP 05089-030, Brazil

Tel. +55-11-37965944

Fax. +55-11-37965944

E-mail: araujojred@terra.com.br

This is an Open Access article distributed under the terms of the Creative Commons Attribution NonCommercial License (http://creativecommons.org/ licenses/by-nc/4.0/) which permits unrestricted noncommercial use distribution, and reproduction in any medium, provided the original work is properly cited.

Copyright @ 2022 Korean Society of Ultrasound in Medicine (KSUM)

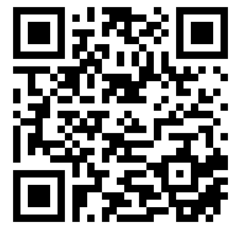

How to cite this article:

Malho AS, Bravo-Valenzuela NJ, Ximenes $\mathrm{R}$ Peixoto $A B$, Araujo Júnior $E$. Antenata diagnosis of congenital heart disease by $3 D$ ultrasonography using spatiotemporal image correlation with HDlive Flow and HDlive Flow silhouette rendering modes. Ultrasonography. 2022 Jul;41(3):578-596. 


\section{Introduction}

According to the World Health Organization, approximately 295,000 newborns die annually due to congenital anomalies during the neonatal period [1]. Congenital heart disease (CHD) is the most frequent type of birth defect and a leading cause of perinatal death due to congenital anomalies. The prevalence of CHD is approximately 8-12 per 1,000 live births, with variation according to the characteristics of the studied population [2].

The prenatal diagnosis of CHD is crucial to improve patient outcomes, especially for fetuses with conditions such as transposition of the great arteries and duct-dependent systemic or pulmonary circulation. Under these circumstances, advances in prenatal ultrasound cardiac screening, and fetal echocardiography are important tools for the early detection of most CHD cases. The International Society of Ultrasound and Gynecology (ISUOG) recommendation of incorporating visualization of the outflow tract views as well as the four-chamber view into the routine prenatal ultrasound assessment of the fetal heart is evidence- based and has been contributed to improve the prenatal CHD detection rate $[3,4]$.

Advanced imaging and Doppler modalities, such as threedimensional (3D) and four-dimensional (4D) ultrasonography, have enhanced the accuracy of prenatal CHD detection by providing high-quality images that enable a detailed analysis of fetal cardiac anatomy and function $[5,6]$. Starting from the acquisition of a fourchamber view of the fetal heart, cardiac volumes can be displayed in both multiplanar and rendering modes, in a static view or in movement (4D), which offers potential advantages over twodimensional (2D) ultrasonography as it is less dependent on the experience of the operator to obtain high-quality images, requiring less time for the fetal cardiac examination $[7,8]$.

In this setting, the HDlive software is a technique for visualizing surface patterns that differs from conventional 3D rendering methods by providing realistic portrayals of the cardiac structures and vessels, especially by adding HDlive Flow [9-15].

In this article, the authors describe how 3D ultrasonography using spatiotemporal image correlation (STIC) in HDlive and the HDlive Flow silhouette rendering mode (General Electric Healthcare, Zipf, Austria) is used to improve CHD prenatal detection by providing a gallery of realistic cardiac images of a variety of types of CHD.

\section{Pulmonary Valve Absence}

Tetralogy of Fallot (TOF) is the most common type of cyanotic CHD; it is a conotruncal anomaly, in which the four-chamber view of the fetal heart is normal as the ventricular septal defect (VSD) is an outflow ventricular defect. VSD malalignment with overriding of the aorta and small pulmonary arteries in the outlet tract views are clues to the diagnosis of the classical form of TOF. Conversely, when TOF is associated with the absence of the pulmonary valve, the pulmonary arteries are enlarged and the pulmonary valve is incompetent. In severe cases, pulmonary hypoplasia or severe airway disease is present due to chronic extrinsic compression of the airways by the aneurysmal pulmonary arteries in utero. The early diagnosis of this

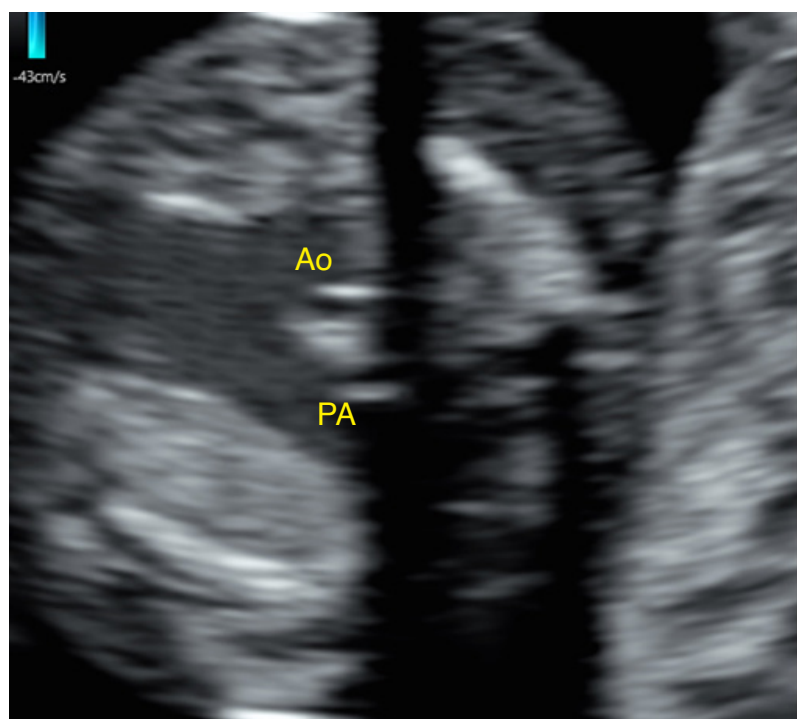

A

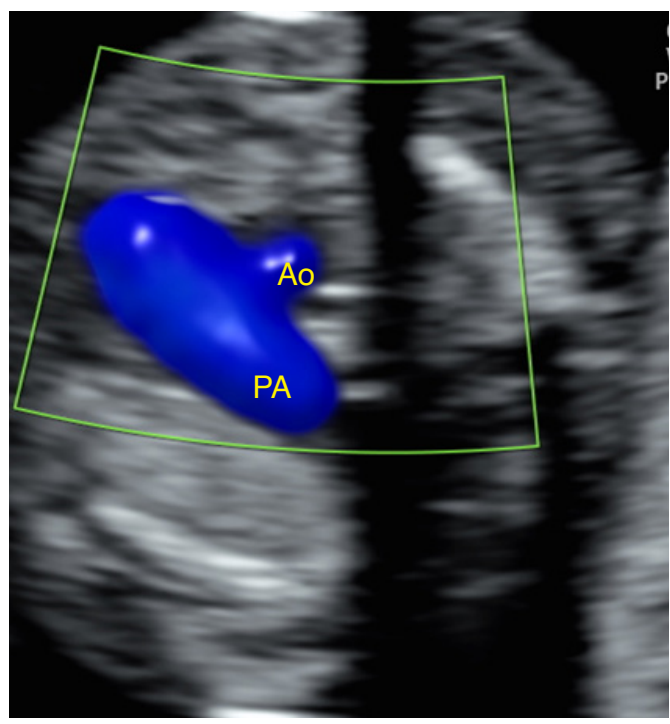

B

Fig. 1. Tetralogy of Fallot with absence of the pulmonary valve.

A first-trimester echocardiogram shows the three-vessel view using two-dimensional ultrasonography (A) and color Doppler imaging (B) with a larger pulmonary artery (PA) than the aorta (Ao) in an unusual disproportion. 
form of TOF is crucial to plan for the delivery in a tertiary center (given the potential need for liquid ventilation and extracorporeal membrane oxygenation at birth) and even termination of pregnancy $[16,17]$. Furthermore, 3D/4D ultrasound allows ventricular outflow tract evaluation, which is useful for detecting pulmonary artery enlargement. In three-vessel and trachea views with color Doppler, it is easy to demonstrate that the pulmonary artery is larger than the aorta if there is an unusual degree of disproportion (Fig. 1). Moreover, reversed flow due to pulmonary valve incompetence can be evaluated even at an early gestational age using consecutive HDlive Flow silhouette rendering mode with better sensitivity than conventional 2D color Doppler (Fig. 2) [10,18].

\section{Tricuspid Dysplasia/Ebstein's Anomaly}

Tricuspid dysplasia (TD) can be distinguished from Ebstein's anomaly (EA) based on the tricuspid valve (TV) attachment due to the tethering of its cusps to the posterior ventricular wall or the

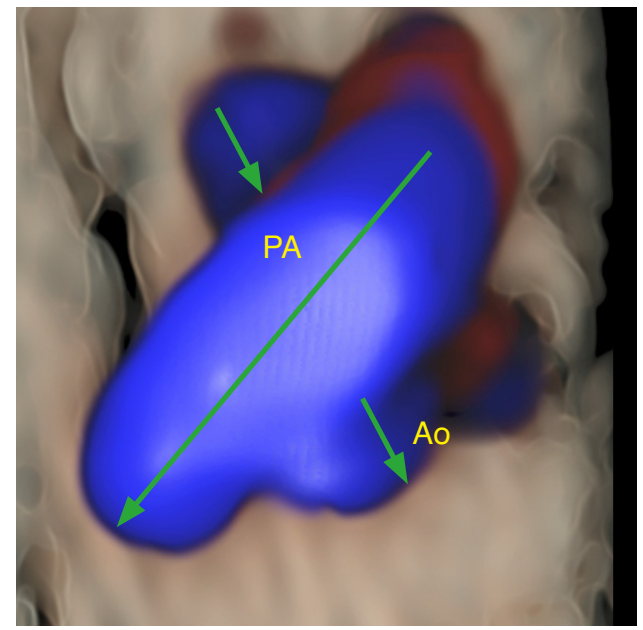

A

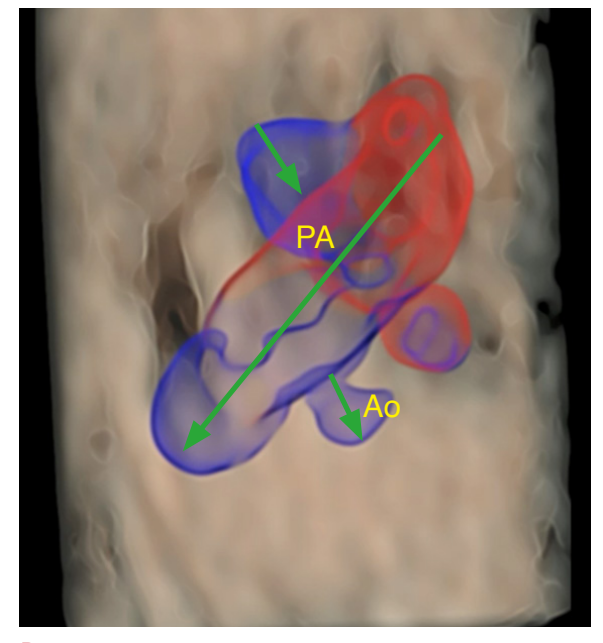

B

Fig. 2. HDlive Flow in a case of tetralogy of Fallot with absence of the pulmonary valve.

Echocardiogram of a fetus at 11 weeks of gestation using three-dimensional ultrasonography with HDlive Flow shows antegrade aorta $(A 0)$ and pulmonary artery (PA) blood flow (A) and retrograde blood flow in the PA due to pulmonary valve incompetence (B).

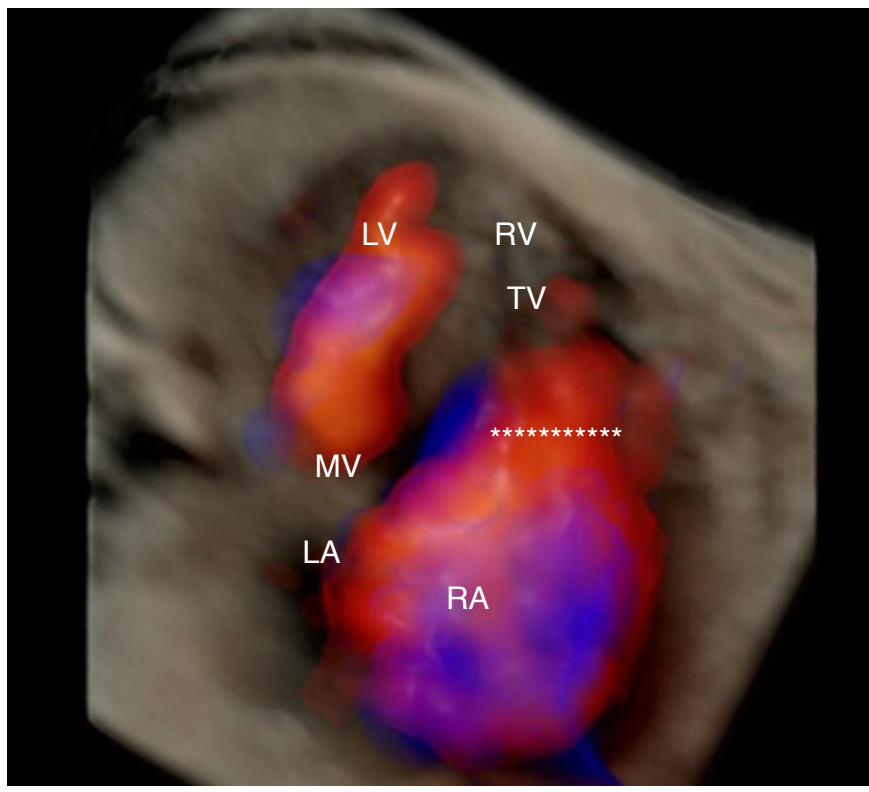

B

Fig. 3. Ebstein's anomaly in a fetus at 27 weeks of gestation.

A. The four-chamber view of the fetal heart using three-dimensional ultrasonography, with HDlive rendering mode enables a realistic image of the low attachment of the tricuspid valve (TV; red arrow) due to the tethering of its cups to the septal surface and the atrialized right ventricle (RV; asterisks). B. HDlive Flow silhouette rendering mode shows the small functional right ventricle and its atrialized portion (asterisks). LA, left atrium; LV, left ventricle; MV, mitral valve; RA, right atrium (anatomical RA+atrialized RV). 
septal surface (Fig. 3). In EA, there is caudal displacement of the septal and posterior leaflets of the TV (distal insertion), while in $T D$, the leaflets do not adhere to the right ventricle wall. Another characteristic that should draw attention to the potential diagnosis of TD is its association with syndromes, such as trisomy 21. The TV has a downward displacement from the atrioventricular ring in $E A$, whereas the TV is located in a normal position, drawing attention to its greater echogenicity (dysplasia), in TD. However, this differentiation may be difficult in borderline cases in which the TV is not very apically displaced or the valve is not extensively deformed, mainly during the first trimester. Advanced ultrasound techniques, such as 3D ultrasonography in rendering mode, enable realistic images of the cusps of the TV and the atrialized portion of the right ventricle in cases of EA [10]. Furthermore, 4D ultrasound STIC color Doppler with glass-body rendering mode is useful for evaluating the degree of tricuspid regurgitation and identifying the presence of other cardiac defects (such as VSD). However, EA and TD may lead to heart failure with a high risk of fetal demise. Hence, an early diagnosis is crucial to optimize prenatal management for fetuses, highlighting the importance of adding the advanced image techniques of 3D/4D ultrasonography to 2D ultrasonography (Fig. 4) [19].

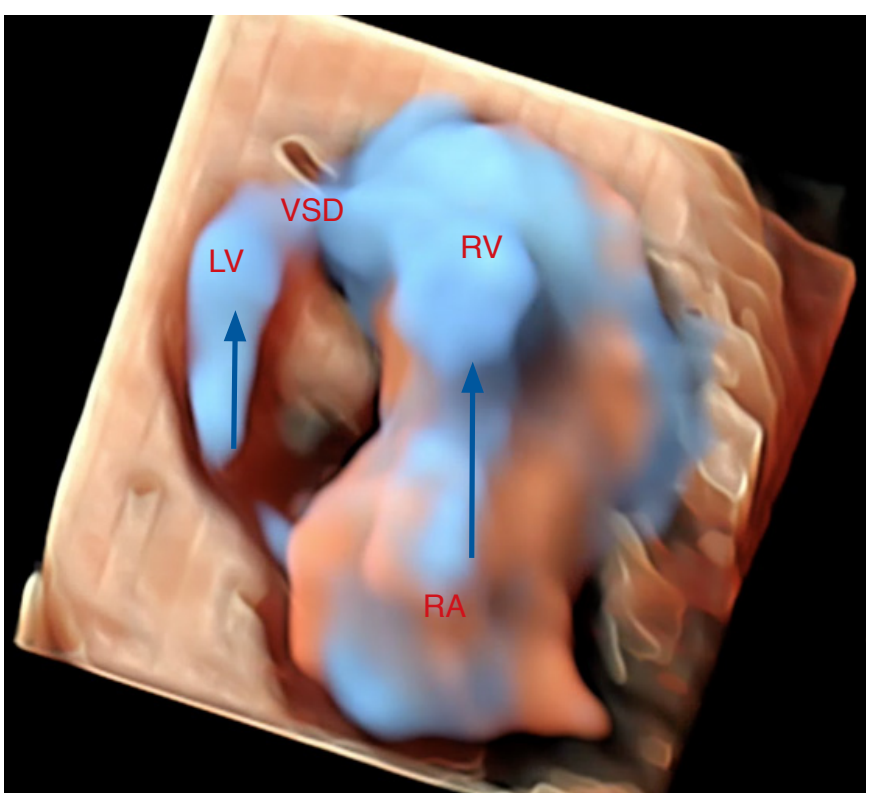

A

\section{Truncus Arteriosus/Pulmonary Atresia with Ventricular Septal Defect}

Truncus arteriosus (TA) is a rare type of CHD in which a single arterial vessel arises from the ventricles, leading to heart failure and cyanosis in the postnatal period. The single arterial trunk provides flow to the systemic, pulmonary, and coronary circulations. Classically, a large VSD malalignment is present in TA and is strongly associated with 22q 11 deletions (Di George syndrome). The four-chamber view is normal in fetuses with TA. Adding the ventricular outflow tract views to the four-chamber view may identify the thickened truncal valve that overrides a large VSD.

Meanwhile, prenatal differentiation between pulmonary atresia (PAt) with VSD and TA can be challenging, mainly in types II and III of TA, as in both conditions a single arterial trunk overrides a VSD (Fig. 5). Thickening of the arterial trunk valve and the absence of the ductus arteriosus are characteristics that should reinforce a clinical suspicion of TA. In contrast, the presence of major aortopulmonary collateral arteries (MAPCA) and the main pulmonary artery without antegrade flow should draw attention to PAt with VSD. The postnatal clinical presentation of PAt with VSD and TA is completely different; being a type of CHD with pulmonary flow dependence on the ductus arteriosus or MAPCA. Conversely, infants with TA develop the clinical signs of heart failure during the first month of life. Therefore,

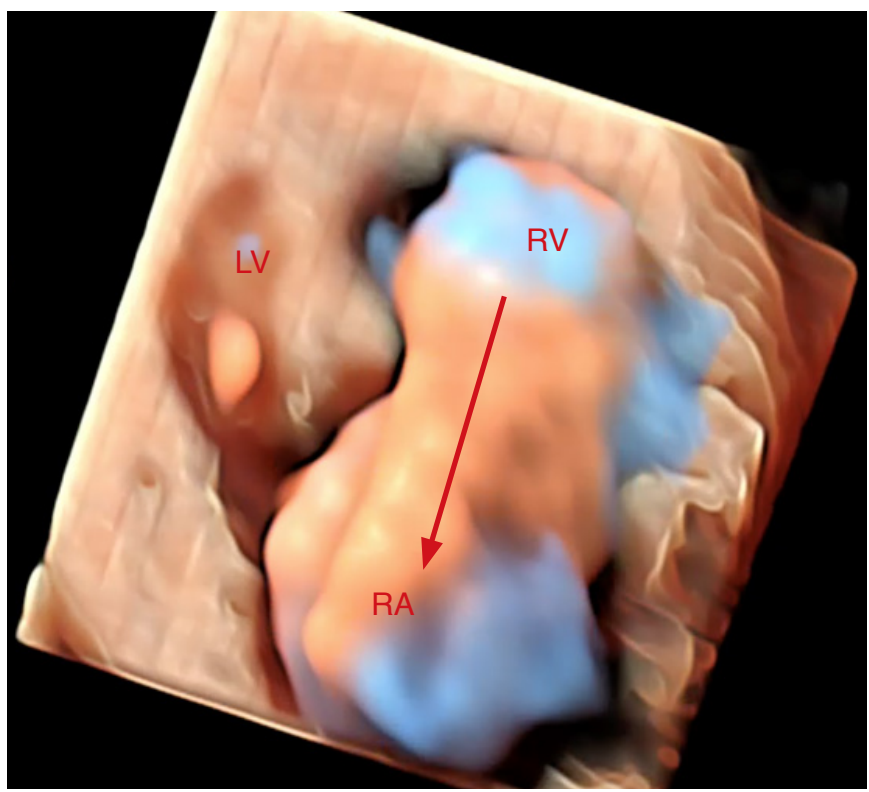

B

Fig. 4. Three-dimensional ultrasonography with HDlive Flow with glass-body rendering mode in a fetus at 13 weeks of gestation with tricuspid dysplasia and a trabecular ventricular septal defect.

Four-chamber view during ventricular diastole demonstrates the flow across the mitral and tricuspid valves (blue arrows) (A) and tricuspid regurgitation during ventricular systole (red arrow) (B). LV, left ventricle; $R A$, right atrium, $R V$, right ventricle. 


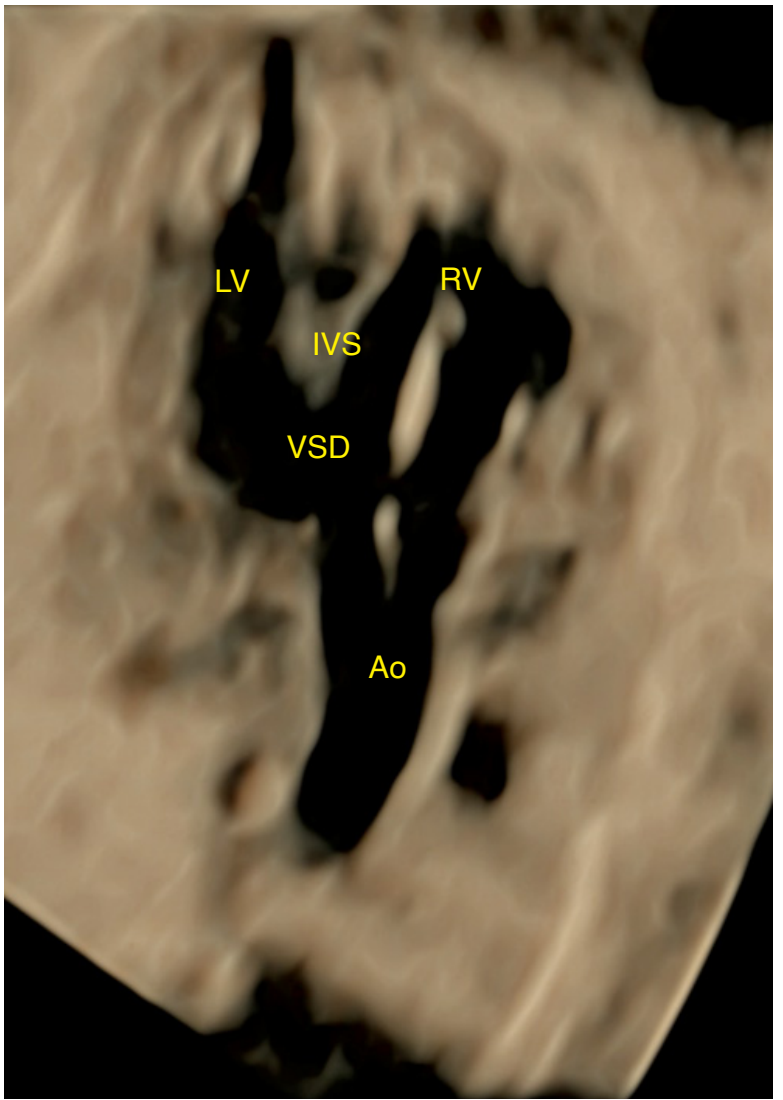

Fig. 5. Tetralogy of Fallot in a fetus at 33 weeks of gestation. HDlive rendering mode enables clear visualization contour of the ventricular septal defect (VSD) malalignment with the aorta shifted slightly to the right and directly above the VSD (overriding of the aorta). Ao, aorta; IVS, interventricular septum; LV, left ventricle; RV, right ventricle. the prenatal differentiation of CHD enables a decisive plan for postnatal management. In those cases, the 4D STIC acquisition of cardiac volumes from a standard four-chamber view fetal heart is an important ultrasound tool that enables detailed ventricular outflow tract reconstruction [20]. With the addition of HDlive Flow and the HDlive Flow silhouette rendering mode, the delineation of the blood vessel walls with a realistic outflow tract reconstruction enables the differential diagnosis between TA and PAt with VSD $[7,9,10]$. Another challenge is to differentiate the types of truncus: type I, the pulmonary trunk arises from the truncal trunk; type II, pulmonary arteries arise from the truncal trunk; type III, one of the pulmonary arteries is absent with collateral circulation; and type IV, TA with an interrupted aortic arch $[16,21]$. HDlive Flow and the HDlive Flow silhouette rendering mode allow the detailed assessment of the truncal arterial trunk anatomy, making it possible to differentiate the types of TA, even during the first trimester of pregnancy (Figs. 6-8) [10].

\section{Hypoplastic Left Heart Syndrome}

Hypoplastic left heart syndrome (HLHS) is characterized by underdevelopment of the left-sided structures of the heart, which are incapable of supporting the systemic circulation. Left ventricular hypoplasia encompasses a wide spectrum of manifestations. Aortic and mitral atresias are described in the classical form of HLHS. In patients with mitral atresia, the left ventricle is severely hypoplastic. Prenatally in such cases, the four-chamber view of the fetal heart is markedly abnormal; therefore, this condition is easy to identify

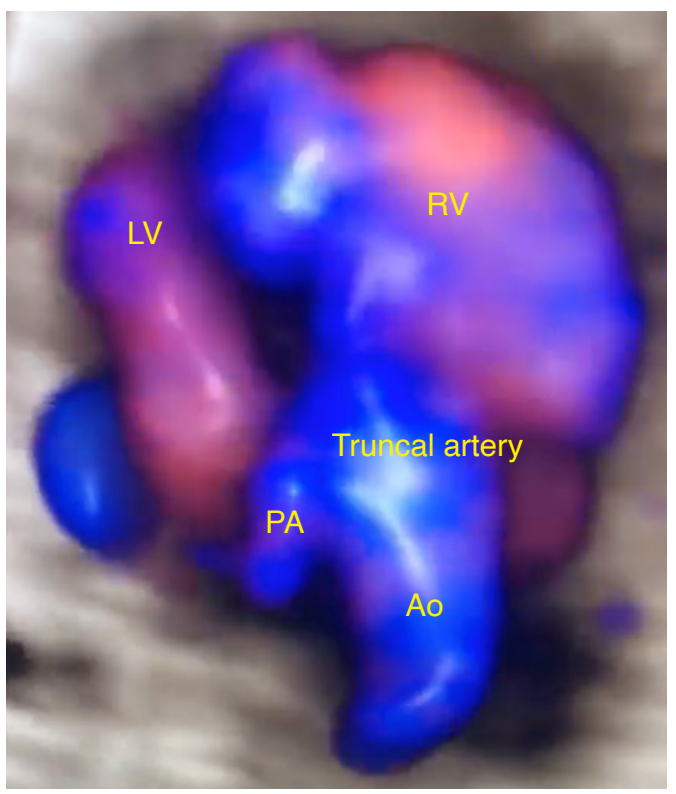

A

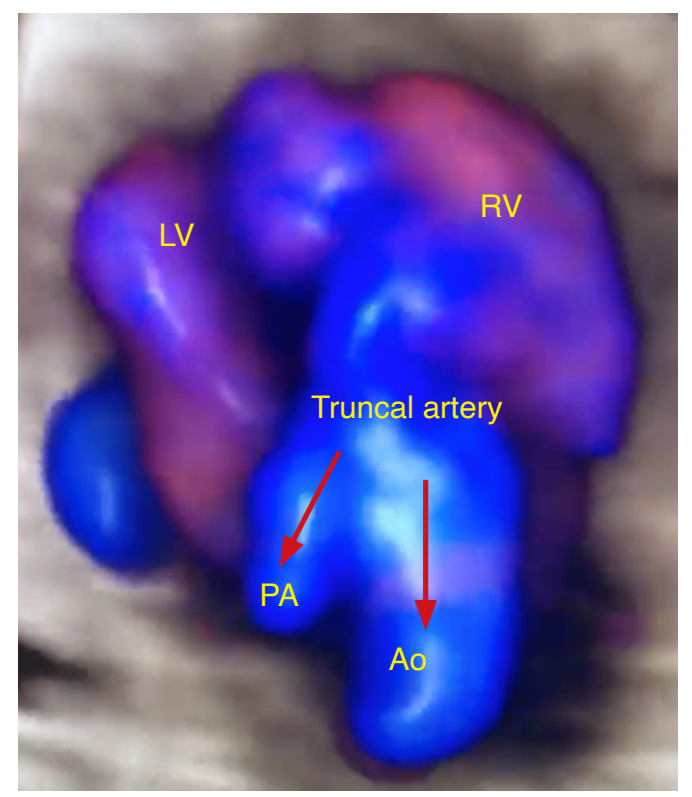

B
Fig. 6. Imaging of the outflow tract using three -dimensional ultrasonogra -phy, with HDlive Flow rendering mode, in a fetus at 16 weeks of gestation with truncus arteriosus type I.

$A, B$. The aorta $(A 0)$ and pulmonary trunk arise from the main truncal artery. Note the unidirectional blood flow in the pulmonary artery (PA) and Ao during ventricular systole (red arrows). LV, left ventricle; $\mathrm{RV}$, right ventricle. 


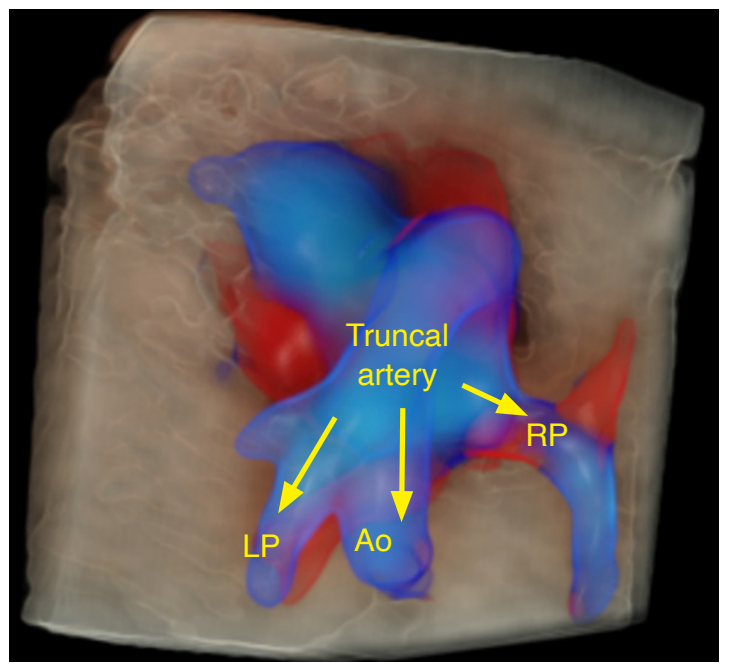

Fig. 7. Imaging of the outflow tract using three-dimensional ultrasonography, with HDlive Flow Silhouette rendering mode in a fetus at 25 weeks of gestation with truncus arteriosus type II. The aorta (Ao), left pulmonary artery (LP), and right pulmonary artery (RP) arise from the main truncal artery. Note the unidirectional blood flow in all truncal artery branches (yellow arrows). through screening with $2 \mathrm{D}$ ultrasonography.

A fetal heart examination using 3D/4D ultrasonography with HDlive and the HDlive silhouette rendering mode enables the detailed assessment of the anatomy of some cardiac structures, which can be crucial for optimizing parental counseling and planning the therapeutic management of HLHS $[3,4]$. The significant difference between the right- and left-sided structures of the fetal heart in the four-chamber view is realistically depicted because HDlive uses a virtual light source and operators can configure the light to enhance the image details (Fig. 9). In cases of HLHS with mitral stenosis, the HDlive Flow rendering mode may clarify the flow across the mitral valve into the diminutive left ventricle (Fig. 10) [912]. In fetuses with HLHS and aortic atresia, reversed flow in the aorta without anterograde flow across the aortic valve is detectable in upper mediastinum views (three vessels and three vessels and trachea views) and the left ventricle outflow tract view (Fig. 11). The significant size difference between arteries due to a hypoplastic aorta and even the reversed flow into the aorta in cases of aortic atresia are more evident using HDlive Flow in the spatial three-

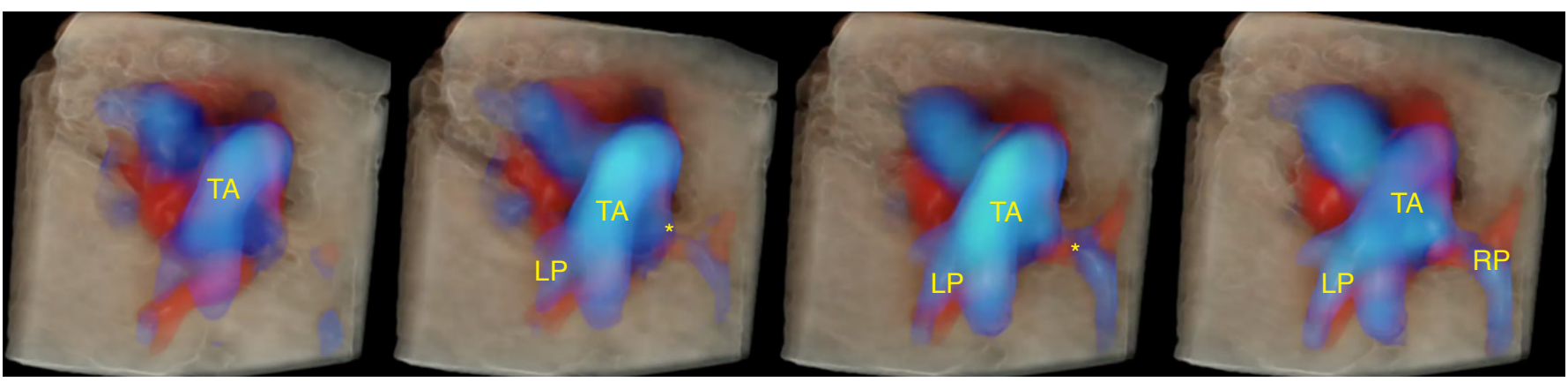

Fig. 8. Assessment of the pulmonary arteries using spatiotemporal image correlation software with the HDlive Flow silhouette rendering mode in a case of truncus arteriosus type II. This technology enables the reconstruction of pulmonary arteries. Note that the right ( $\left.{ }^{*} \mathrm{RP}\right)$ and the left pulmonary arteries (LP) arise from the main arterial trunk. ${ }^{*}$, reconstruction of the right pulmonary artery arising from the main truncal artery; $T A$, main truncal artery.

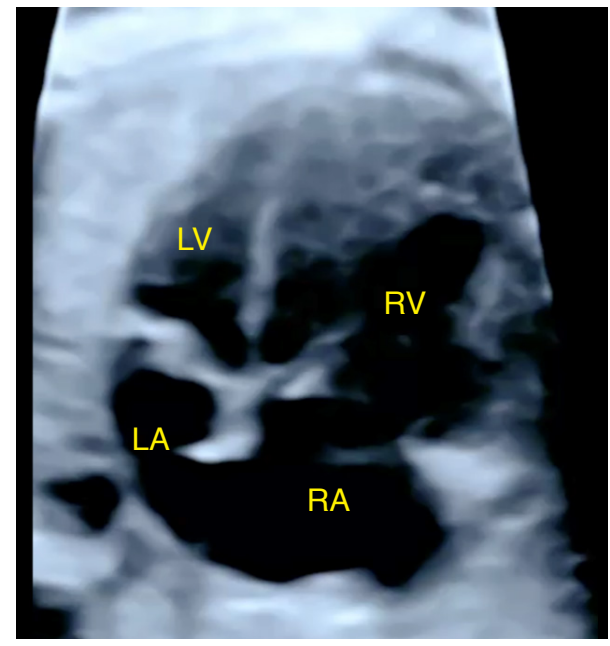

A

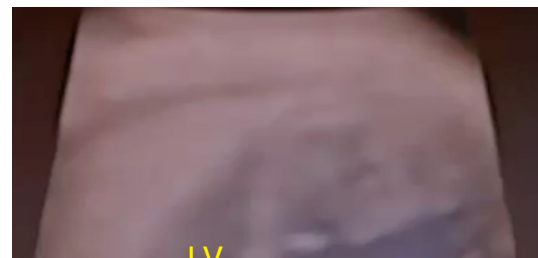

RV

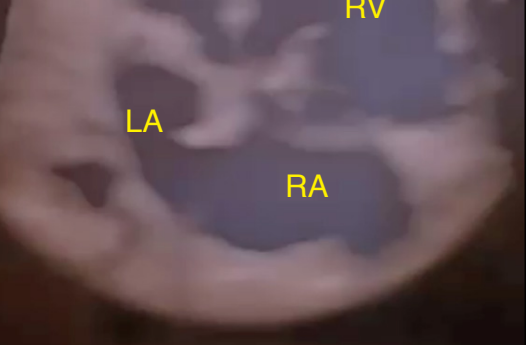

B

Fig. 9. Discrepancy between the right and left-sided structures of the fetal heart in a fetus at 21 weeks of gestation with hypoplastic left heart syndrome.

Three-dimensional ultrasonography images of the four-chamber view of the fetal heart with HDlive rendering (A) and HDlive silhouette rendering modes (B) show a hypoplastic left ventricle, small left atrium, and thick mitral valve. $L A$, left atrium; $L V$, left ventricle; $R A$, right atrium; RV, right ventricle. 
vessel view (Figs. 11, 12). Furthermore, the HDlive Flow rendering mode provides realistic contours of the small ascending aorta in the aortic arch sagittal view (Fig. 13).

\section{Pulmonary Atresia with Intact Ventricular Septum}

PAt is a rare type of CHD, in which a connection is absent between the right ventricle and the pulmonary circulation, associated with

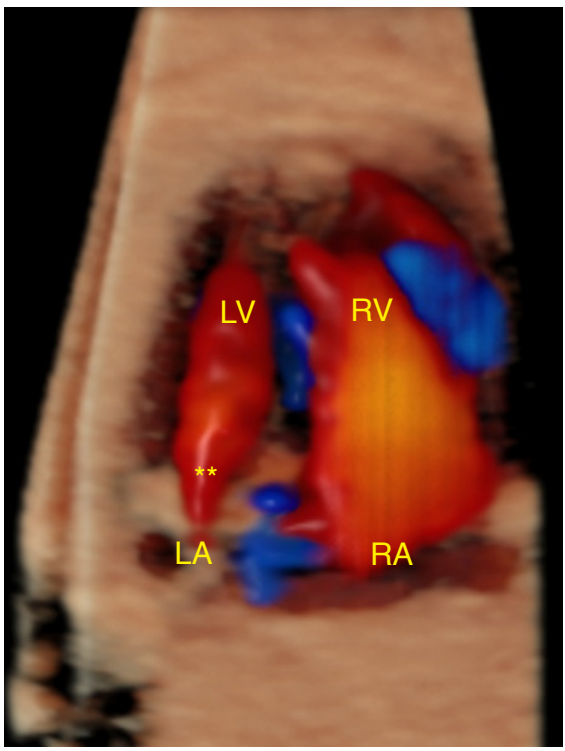

A

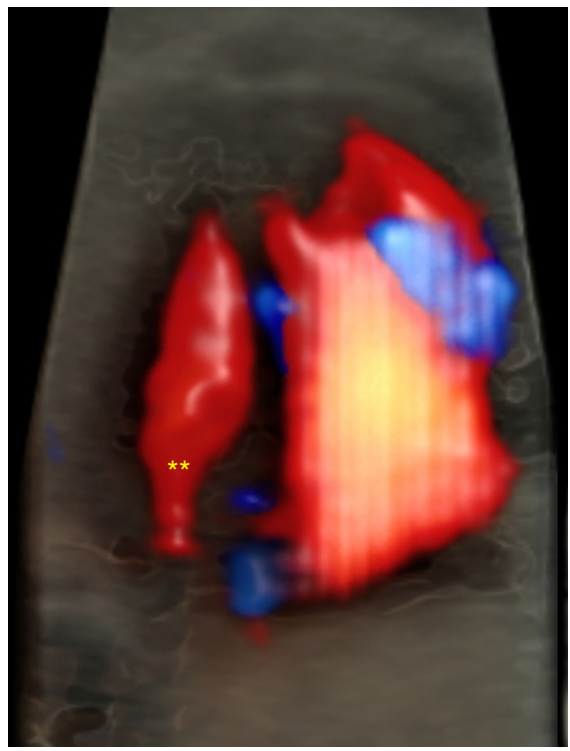

B

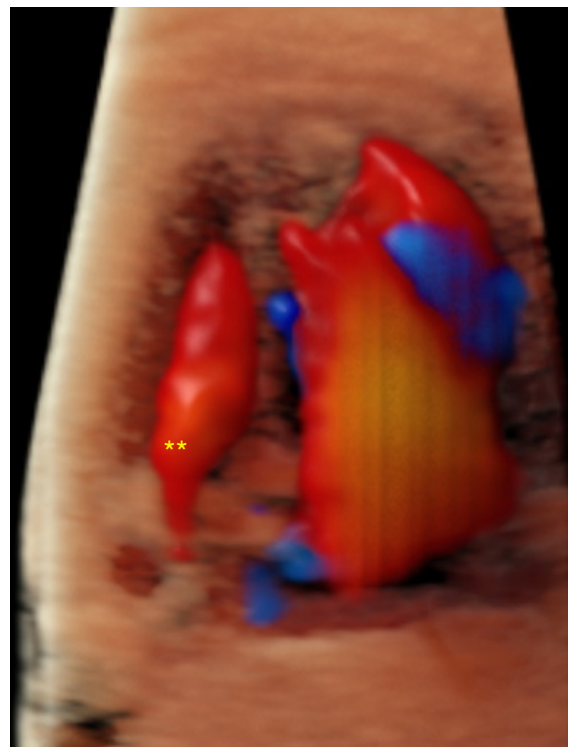

C

Fig. 10. Hypoplastic left heart syndrome (HLHS) with mitral valve stenosis in a fetus at 21 weeks of gestation.

Imaging of the four-chamber view of the heart using three-dimensional ultrasonography, with HDlive Flow $(A, C)$ and HDlive Flow silhouette (B) rendering modes in a case of HLHS with mitral valve stenosis is shown. The HDlive Flow rendering mode shows small blood flow across the mitral valve (asterisks) into the diminutive left ventricle. $L A$, left atrium; $L V$, left ventricle; $R A$, right atrium; RV, right ventricle.

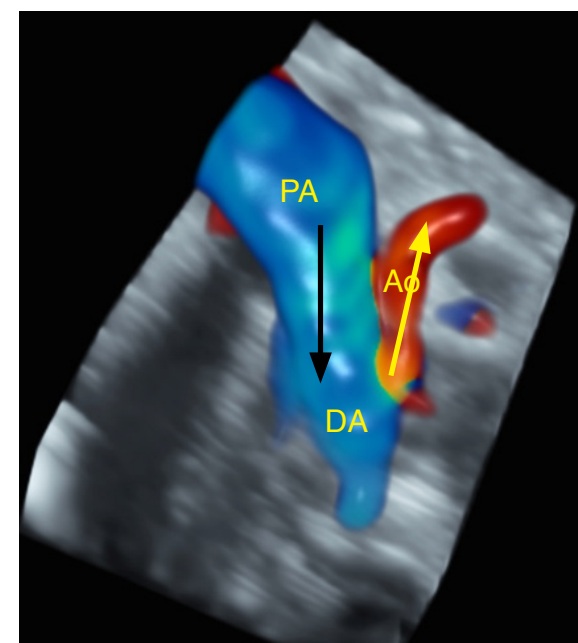

A

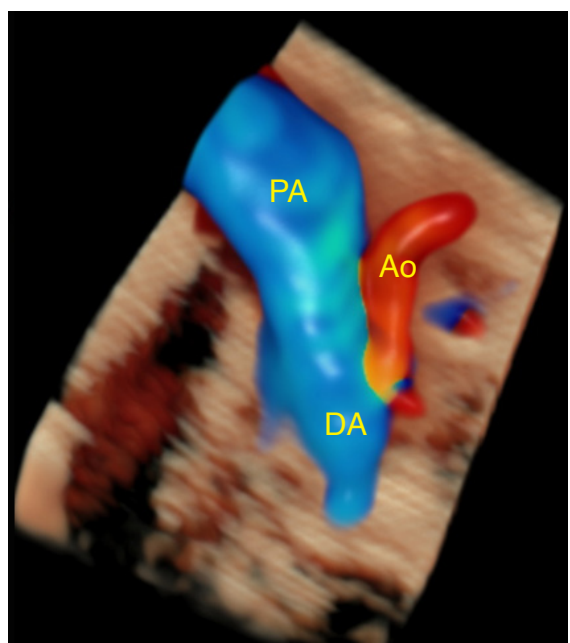

B

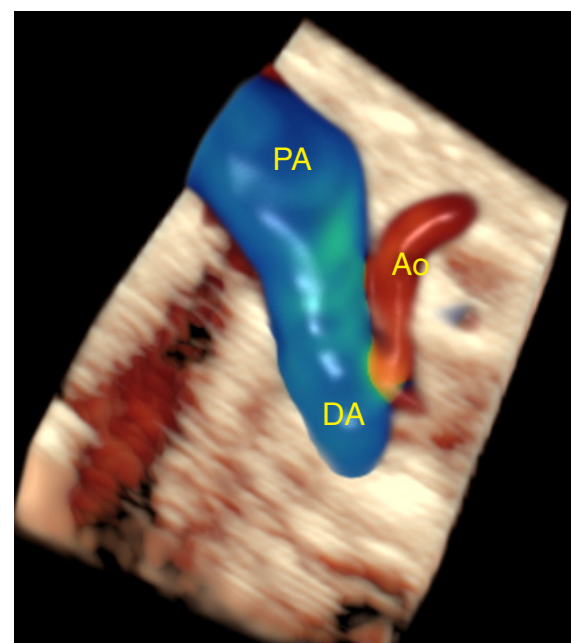

C

Fig. 11. Hypoplastic left heart syndrome (HLHS) with aortic atresia.

Imaging of three-vessel and trachea view using three-dimensional ultrasonography with HDlive Flow $(A)$ and HDlive Flow silhouette ( $B$, C) rendering modes in a fetus with HLHS and aortic stenosis. The pulmonary artery (PA) blood flow has a usual anterograde direction (black arrow). The blood flow crosses the ductus arteriosus (DA) toward the aortic artery. Note the reversed flow of the aorta (Ao) without anterograde flow across the aortic valve (yellow arrow). 


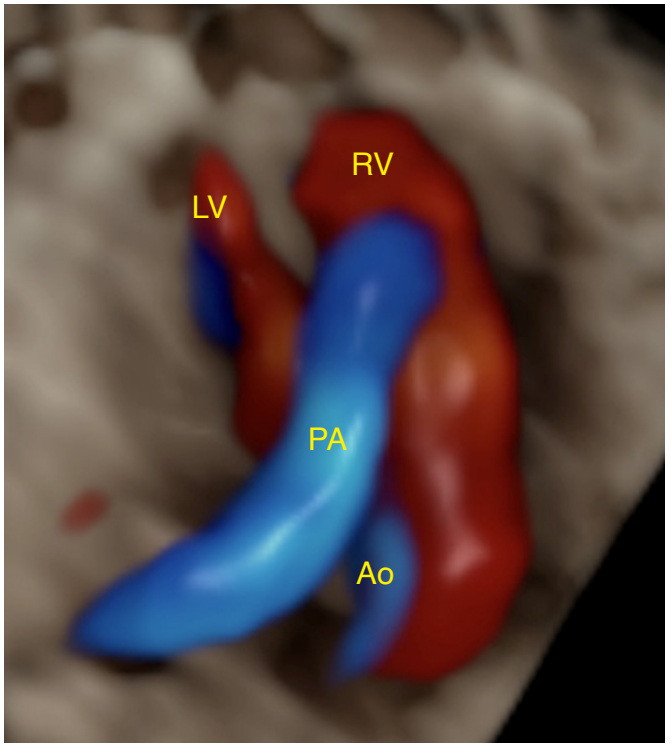

A

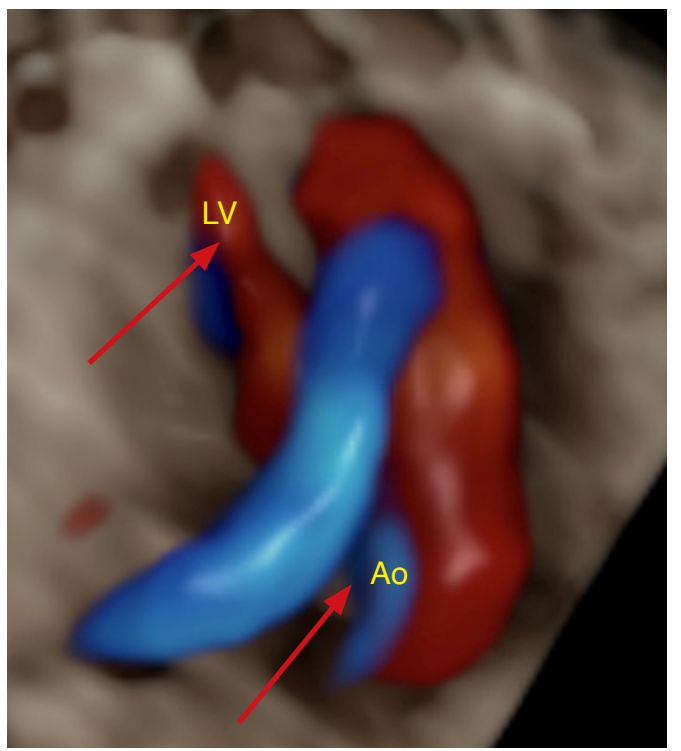

B

Fig. 12. Hypoplastic left heart syndrome with aortic stenosis.

Images of the outflow tracts using three-dimensional ultrasonography with HDlive Flow rendering mode show the significant difference in size between the pulmonary artery (PA) and aorta ( $\mathrm{Ao})$ $(A)$, and the anterograde blood flow in the PA and Ao (B). Note the hypoplastic left ventricle (LV) and Ao (red arrows). RV, right ventricle.

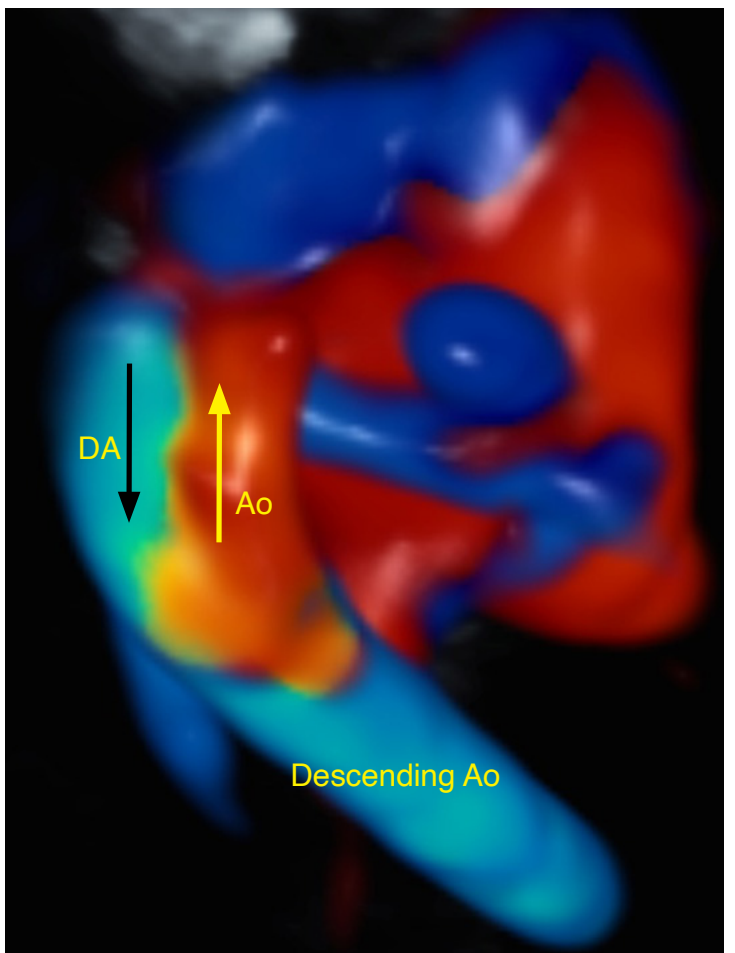

Fig. 13. Reversed flow into the aortic arch in a fetus with hypoplastic left heart syndrome. HDlive Flow rendering mode provides the realistic contour of the small ascending aorta (Ao). Reversed flow into the aortic arch can be detected as a marker of congenital heart disease with ductal dependence of the systemic ductal circulation. The yellow arrow and the black arrow show the direction of the blood flow. DA, ductus arteriosus. an intact ventricular septum (IVS). The classification of PAt varies according to the TV features. In cases of PAt and TV stenosis, the right ventricle is hypoplastic (type I), whereas in type II, the right ventricle is well-developed and the right atrium is enlarged as the TV is dysplastic and incompetent. In type I, the four-chamber view of the fetal heart is abnormal due to the hypoplastic right ventricle. HDlive Flow may provide realistic images of the hypoplastic right ventricle and the IVS (Fig. 14) $[7,14]$. The right ventricular outflow tract view enables identification of an immobile and thickened pulmonary valve and the presence of reversed flow in the pulmonary artery and the absence of flow through the pulmonary valve, with with reversed flow into the pulmonary artery by color Doppler imaging. In cases of PAt with IVS, the pulmonary artery is, in general, smaller than the aorta on the three-vessel view $[7,16]$.

\section{Tricuspid Atresia}

Tricuspid atresia is defined as agenesis of the TV without direct communication between the right atrium and the right ventricle. This defect is associated with normally related (type I) or transposed arteries (types II and III: D and L transposed arteries). The pulmonary flow could be normal, decreased (pulmonary stenosis), or absent (PAt). If the VSD is absent or small, the restricted flow to the right ventricle can lead to severe right ventricular hypoplasia.

Prenatal diagnosis of tricuspid atresia is easily done by ultrasonography using a four-chamber view. In fetuses with tricuspid atresia, characteristics of an imperforated TV, absence of flow across the TV on color Doppler during diastole, and a hypoplastic right 
ventricle with or without VSD can be assessed with high image quality using 3D ultrasonography with the HDlive Flow rendering mode (Fig. 15) $[14,15]$. After birth, patients with PAt with IVS require administration of prostaglandin $\mathrm{E} 1$ at birth to maintain patent ductus arteriosus until surgery is performed to improve perinatal outcomes.

\section{Ventricular Septal Defect}

VSD is the most common type of CHD; meanwhile, those defects

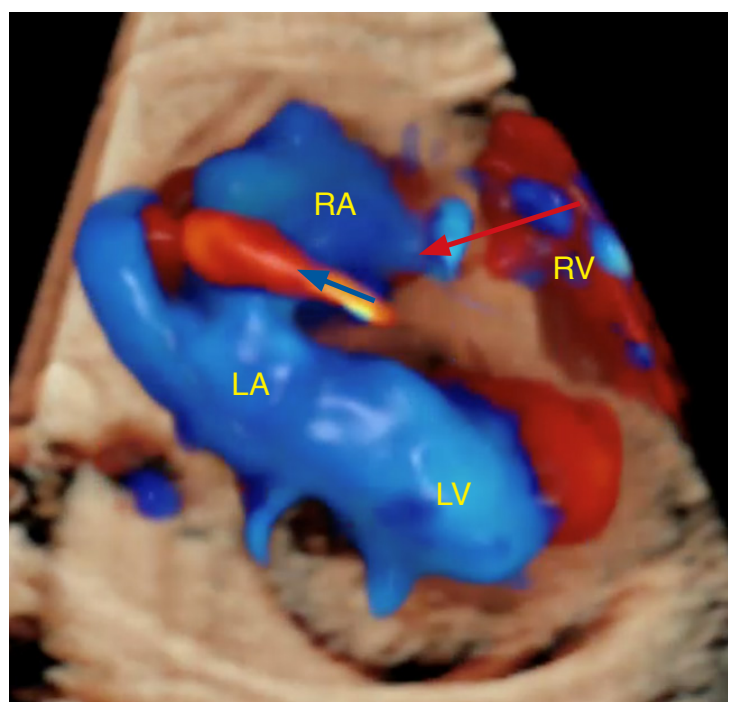

Fig. 14. Imaging of the four-chamber view of the fetal heart with HDlive Flow silhouette rendering mode in pulmonary atresia with an intact ventricular septum. Tricuspid stenosis (red arrow) with tricuspid regurgitation (blue arrow) is observed with color Doppler. $L A$, left atrium; $L V$, left ventricle; $R A$, right atrium; $R V$, right ventricle. are perhaps the most commonly missed in utero. VSD is commonly associated with other cardiac defects, and small and muscular defects present a greater chance to spontaneously close, even in utero. No hemodynamic significance was found during fetal life; however, some cases of VSD may require postnatal surgical interventions depending on the type and shunt magnitude. Furthermore, fetal chromosomal anomalies should be suspected if the defect is large and extends to the inlet septum, as this combination is disproportionately common.

The use of 2D ultrasonography with color Doppler may raise the suspicion of VSD, with care taken to maintain a lateral view of the ultrasound insonation angle. The operator should add the outflow tract view evaluation, as the four-chamber view appears normal in such cases, to identify outflow septal ventricular defects and conotruncal anomalies (malaligned VSD). An advanced approach using 4D-STIC with HDlive Flow may improve the prenatal diagnosis of VSD [26]. The navigation point can be placed on the ventricular septum, enabling a realistic image of the defect with details (size, type, number, and shunting) (Figs. 16-18) [22].

\section{Atrioventricular Septal Defects}

Atrioventricular septum defect (AVSD) refers to a complex group of $\mathrm{CHDs}$, resulting from failure of the atrioventricular septum to fuse. The complete form of AVSD is one of the most common types of CHD detectable in utero and is characterized by a common atrioventricular valve, an ostium primum atrial septal defect, and an inlet VSD. AVSD is categorized as partial or incomplete when the common valve is divided into two atrioventricular valves. The classical partial form of AVSD also combines an ostium primum atrial defect and a left valve orifice cleft. Indeed, AVSD has a strong

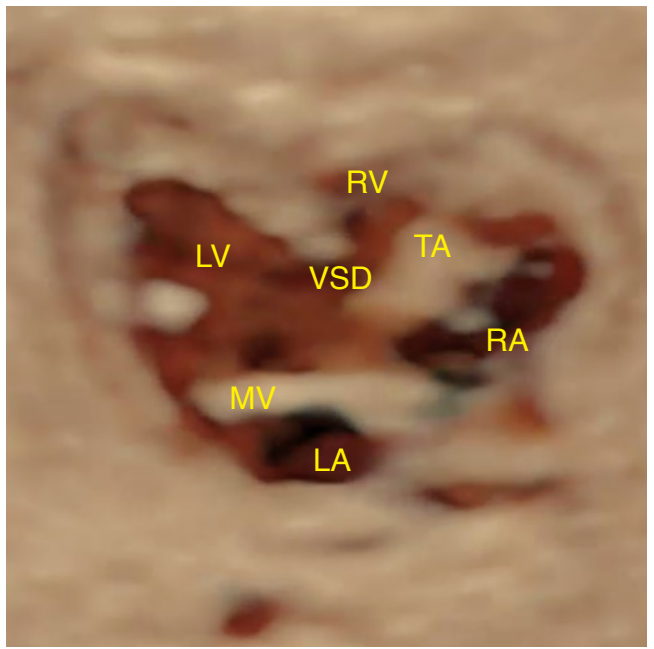

A

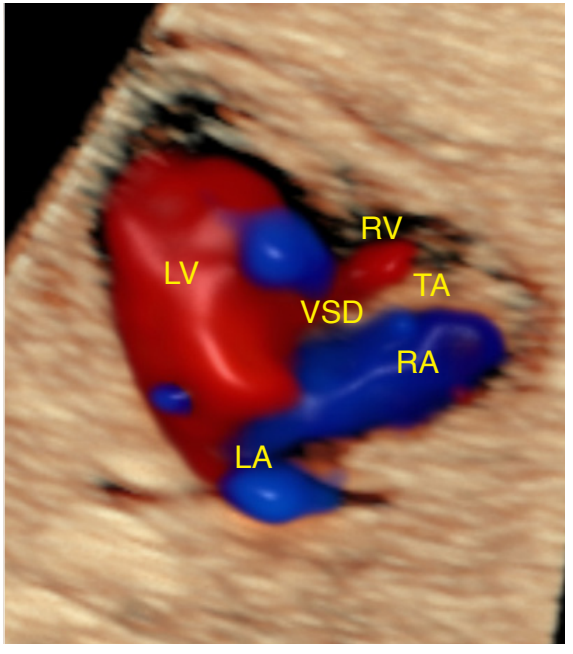

B
Fig. 15. Tricuspid atresia (TA) with small ventricular septal defect (VSD) in a fetus at 21 weeks of gestation.

A. Three-dimensional ultrasonography imaging of the four-chamber view of the heart using HDlive silhouette rendering mode shows the thick tricuspid valve and hypoplastic right ventricle (RV). B. The HD live flow rendering mode demonstrates the absence of flow across the tricuspid valve during diastole (TA). The VSD enables a small amount of blood flow to cross from the left ventricle (LV) toward the right RV. LA, left atrium; $M V$, mitral valve; $R A$, right atrium. 


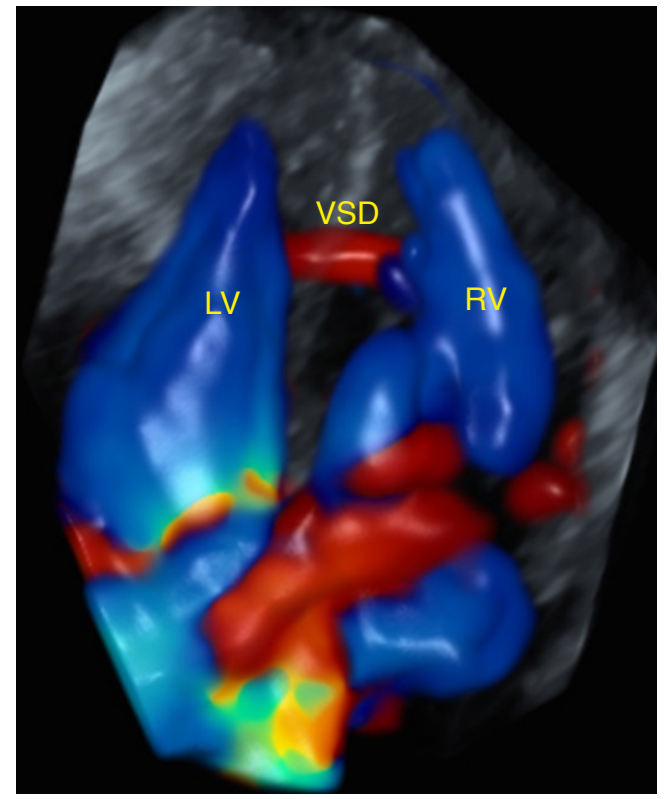

A

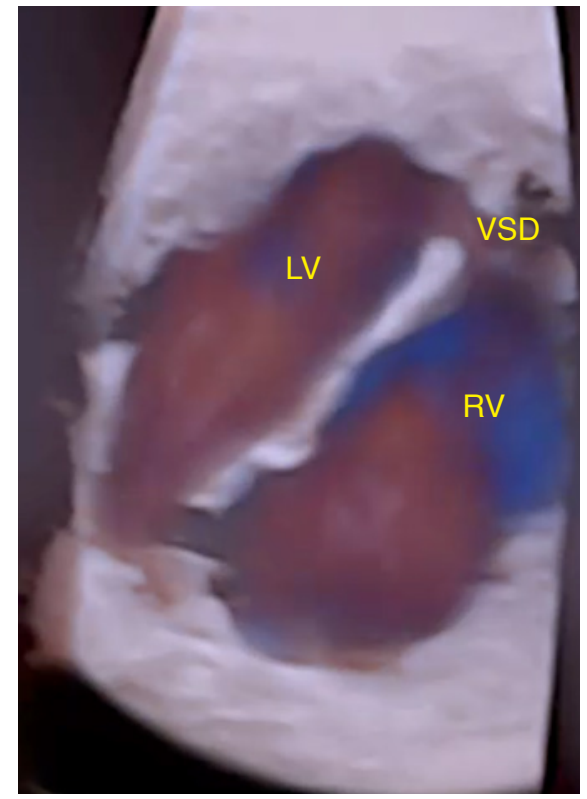

B
Fig. 16. Imaging of the fourchamber view of the heart using three-dimensional ultrasonography in a fetus with ventricular septum defect (VSD).

Three-dimensional color Doppler (A) and HDlive Flow with glass-body rendering mode (B) show a realistic apical muscular VSD and detailed assessment of the shunting across the defect. $L V$, left ventricle; $R V$, right ventricle.

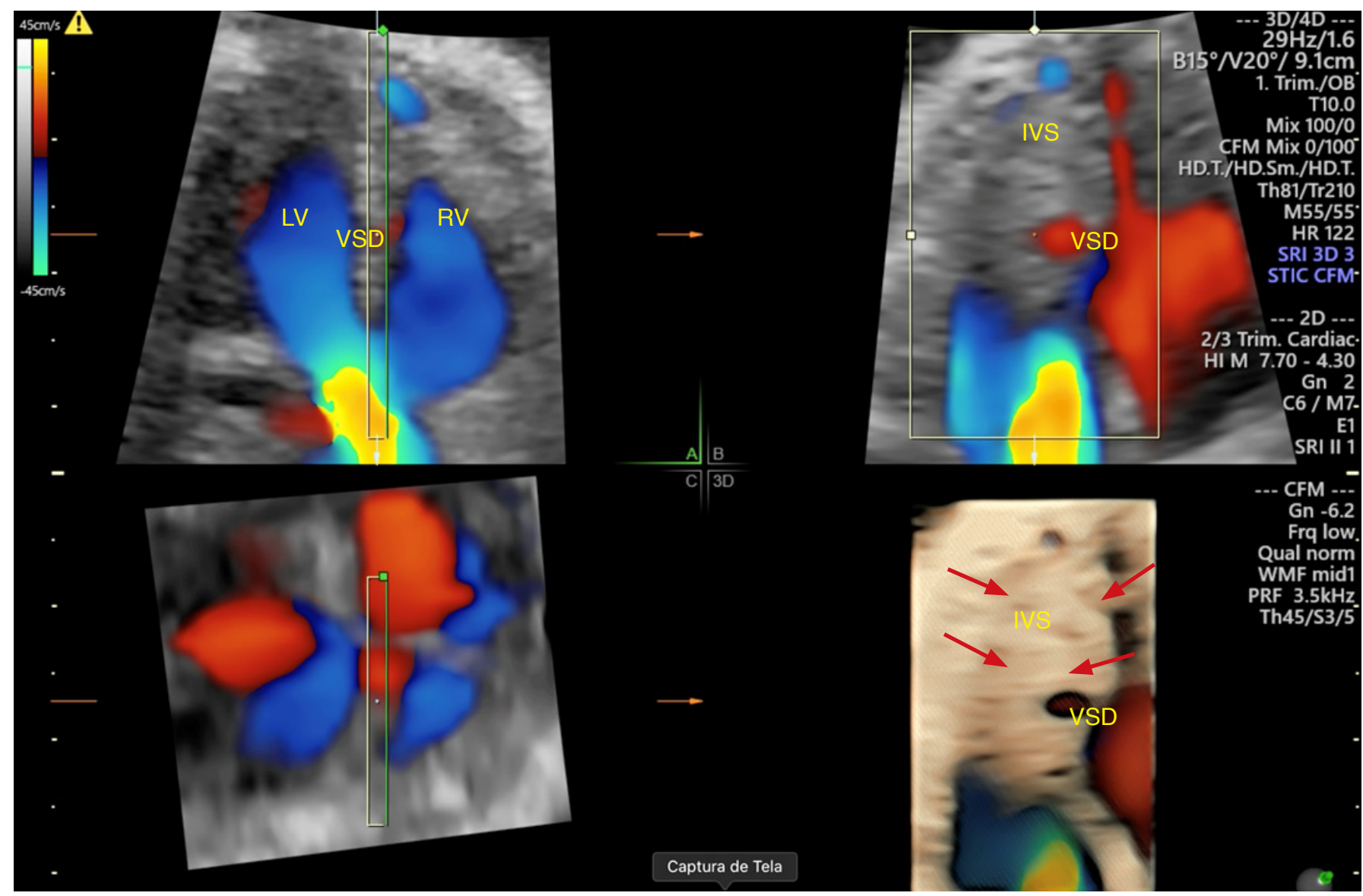

Fig. 17. Advanced approach using three-dimensional (3D) spatiotemporal image correlation with multiplanar color Doppler and HDlive Flow rendering modes in a fetus at 26 weeks of gestation with a ventricular septal defect. The navigation point should be placed on the ventricular septum to enable a realistic image of the defect with details. The 3D rendering mode shows a unique small elliptic ventricular septal defect. Note that the other regions of the ventricular septum are intact (red arrows). IVS, intact ventricular septum; LV, left ventricle; $\mathrm{RV}$, right ventricle; VSD, ventricular septum defect. 
association with Down syndrome, and the fetal karyotype should be discussed with parents whenever this diagnosis is carried out.

Complete AVSD is easily diagnosed in fetuses using 2D ultrasound in the four-chamber view. The best diagnosis clues are the absence of the crux of the heart, the presence of a primum atrial septal defect, and the absence of the usual atrioventricular valve offset. Outflow tract views can identify the characteristics of left ventricular outflow in AVSD-specifically, a narrowed and elongated outflow (also known as a gooseneck) $[4,16]$. Using the 3D ultrasound rendering mode, natural and anatomically realistic images of the

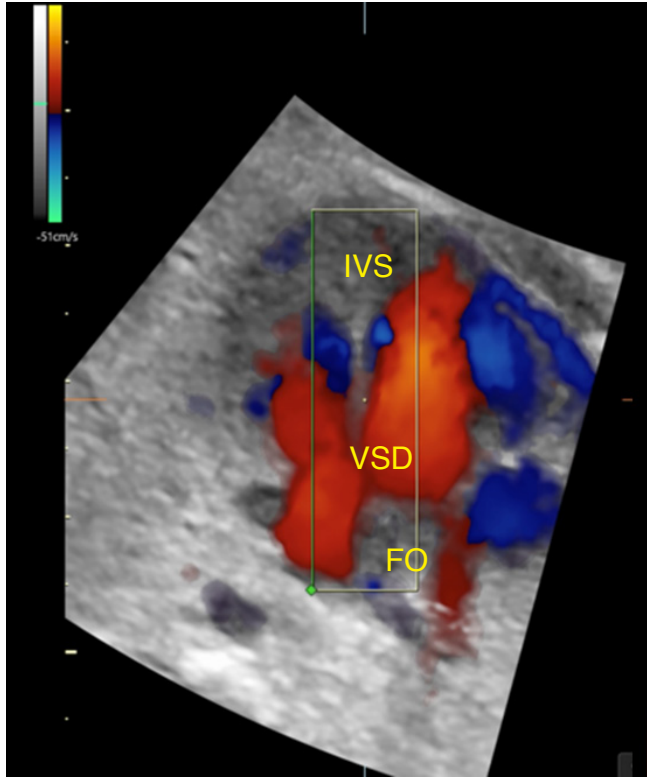

A

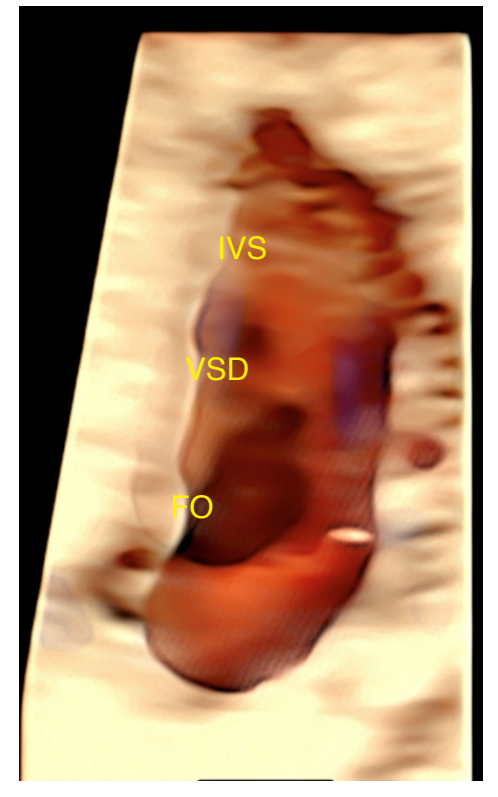

B
Fig. 18. Advanced approach using threedimensional spatiotemporal image correlation with multiplanar color Doppler and HDlive Flow rendering modes in a fetus at 26 weeks of gestation with inlet ventricular septal defect (VSD).

A. The navigation point is placed on the ventricular septum with the region of interest enabling vision from the left ventricle to the ventricular septum. B. The HDlive rendering mode shows a clear view of the foramen ovale (FO) and the inlet VSD. IVS, interventricular septum.

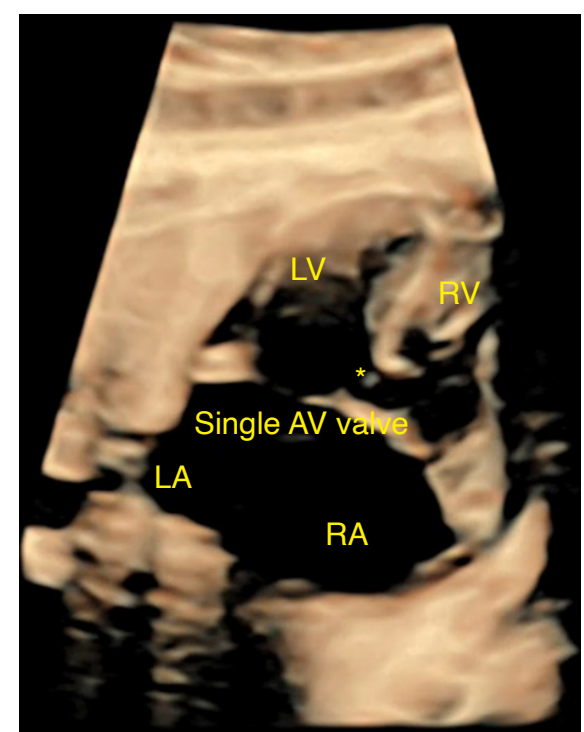

A

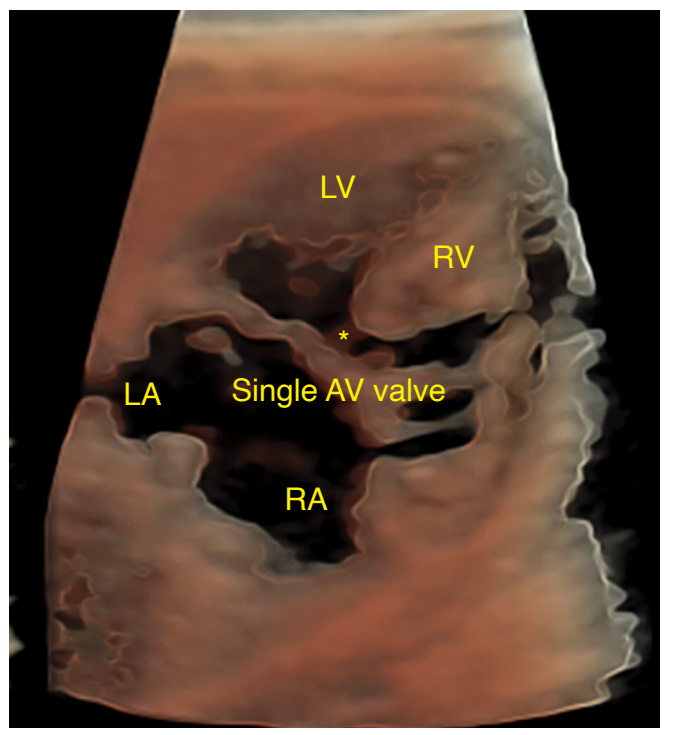

B

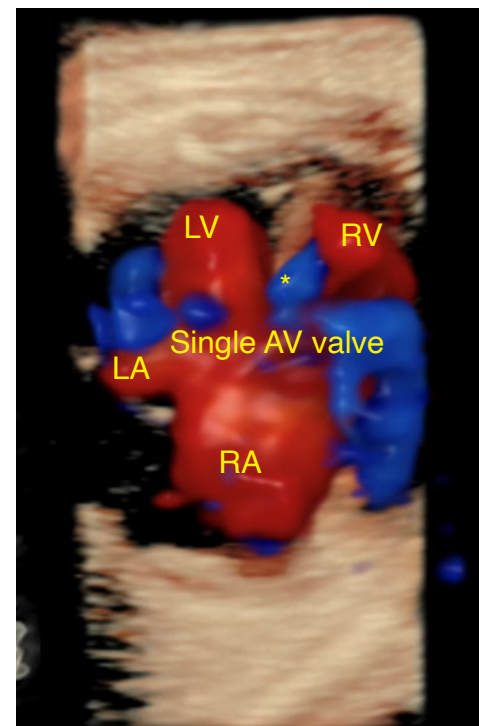

C

Fig. 19. Imaging of the four-chamber view of the heart in a fetus at 21 weeks of gestation with complete atrioventricular septum defect (AVSD).

HDlive (A), HDlive silhouette (B), and HDlive Flow (C) rendering modes enable the assessment of the characteristics of the complete AVSD, which consists of a common atrioventricular (AV) valve, an ostium primum atrial septal defect, and an inlet ventricular septal defect ${ }^{*}$ ). The HDlive Flow rendering mode allows the detection of a balanced form of AVSD, with equally distributed flow inside the right ventricle (RV) and the left ventricle (LV). LA, left atrium; RA, right atrium. 
common atrioventricular valve with the details of its attachment are obtained (Fig. 19) [22].

\section{Right Aortic Arch and Vascular Ring}

Right aortic arch is commonly associated with conotruncal anomalies, such as TOF or TA. A right-sided descending aorta is

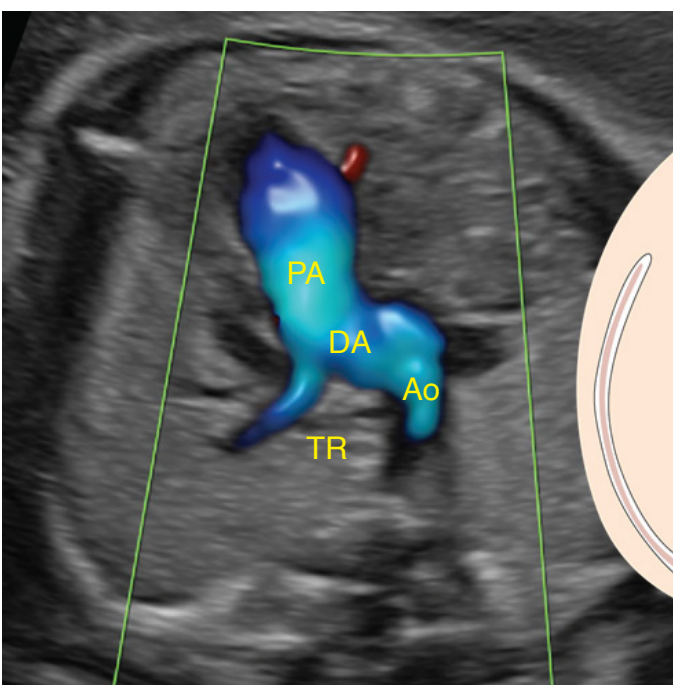

A

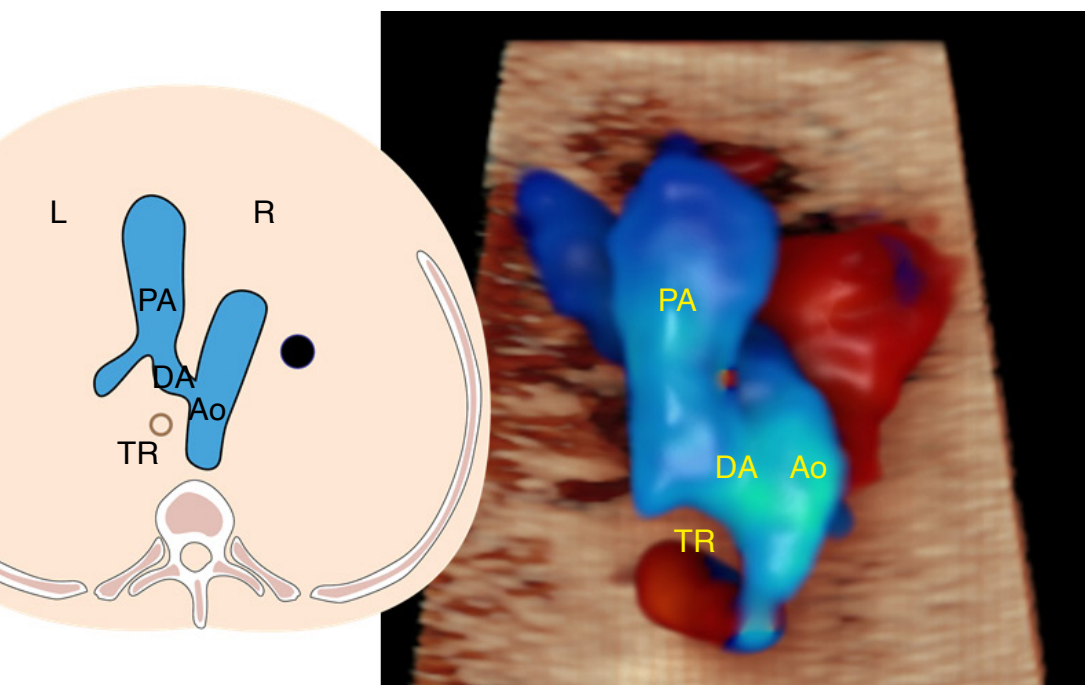

B

Fig. 20. Right-sided aortic arch in a fetus at 24 weeks of gestation.

Images of the three-vessel and trachea view with two-dimensional (2D) color Doppler (A) and 3D HDlive Flow rendering (B) modes show the ductus arteriosus (DA) and aorta (Ao) located at the right side of the trachea (TR). PA, pulmonary artery; R, right side; L, left side.

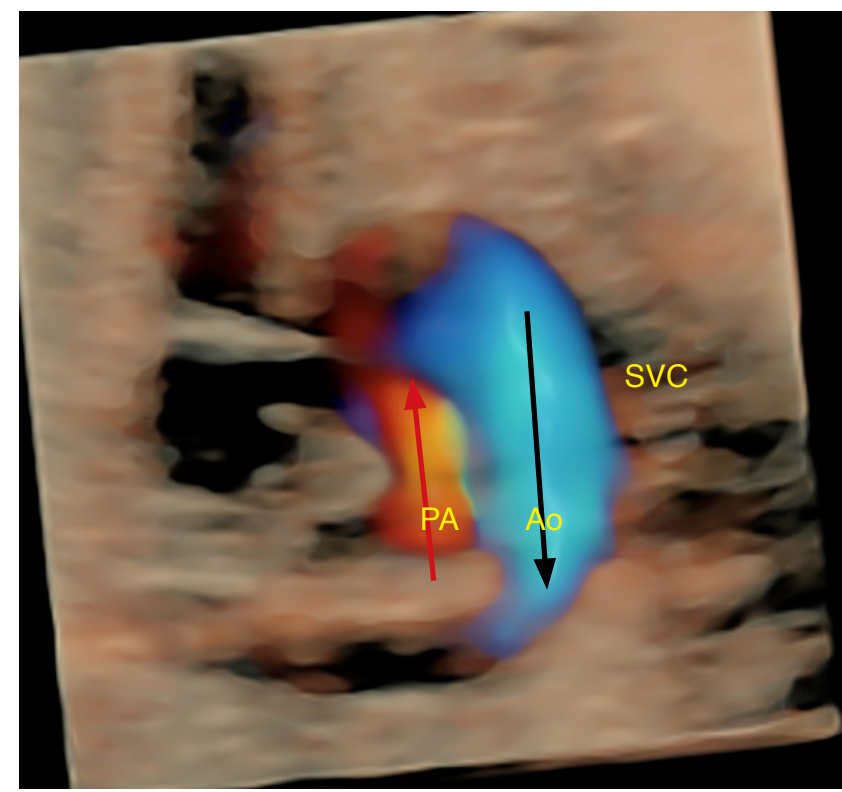

A

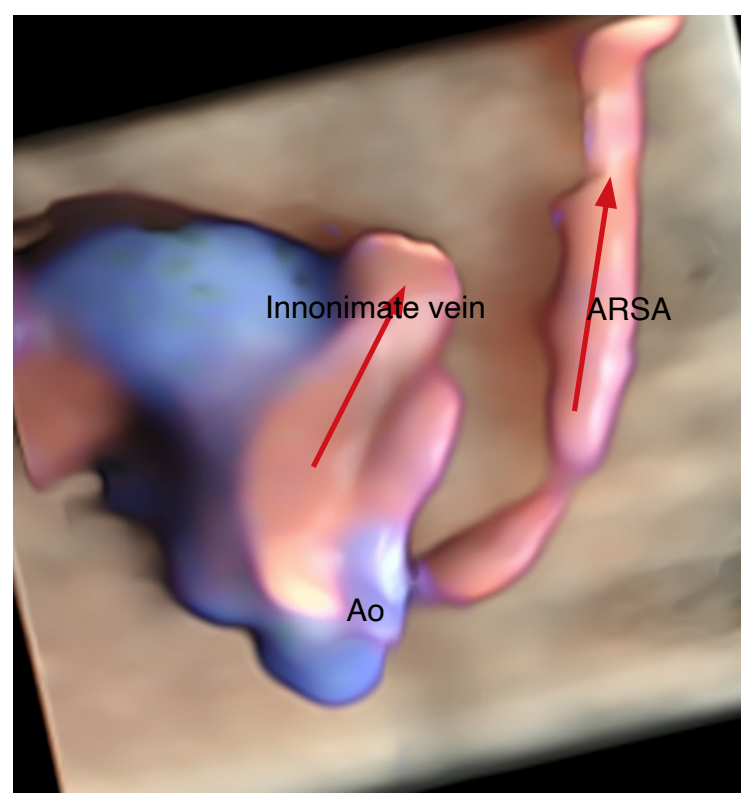

B

Fig. 21. Aberrant right subclavian artery (ARSA) arising from the right-sided aortic arch in a case of pulmonary atresia.

Three-dimensional ultrasonography imaging of the mediastinum view using HDlive Flow silhouette rendering shows the reversed flow into the pulmonary artery (PA; pulmonary atresia) (A) and the location of the right-sided aortic arch with the ARSA (B). Red and black arrows show the direction of the blood flow. SVC, superior vena cava; Ao, aorta. 
observed in the three-vessel and trachea view (the aortic artery is located at the right side of the trachea) (Fig. 20). Vascular rings are congenital anomalies in which a vessel partly or completely encircles the trachea, the esophagus, or both, causing postnatal digestive and/or respiratory symptoms. Abnormal brachiocephalic arterial branches, such as an aberrant subclavian or innominate artery, are not uncommon in right-sided aortic arch with vascular ring anomaly and can be observed in upper mediastinum views (Fig. 21). A gap between the pulmonary trunk and the ascending aorta and a U-shaped vascular loop enable this diagnosis in the

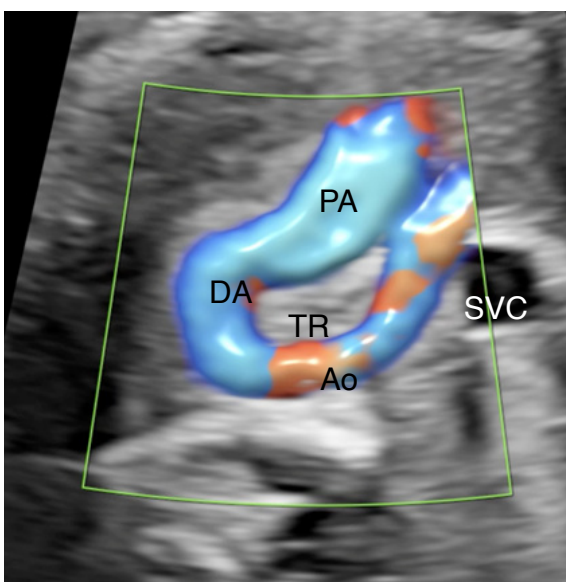

A

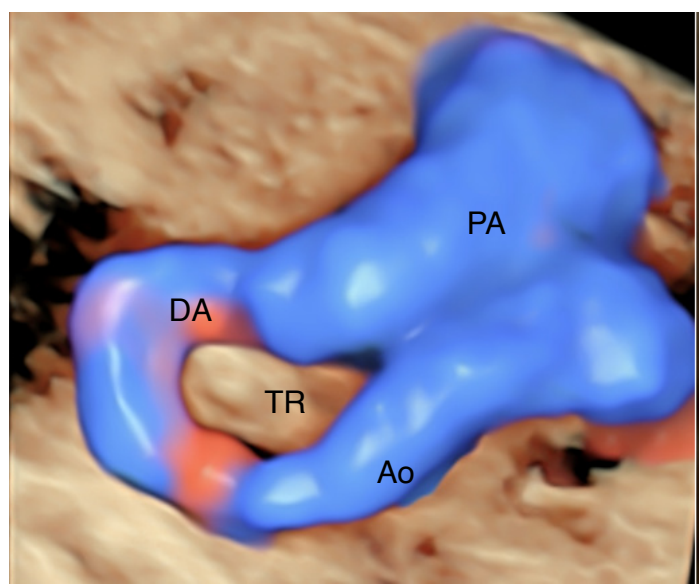

B

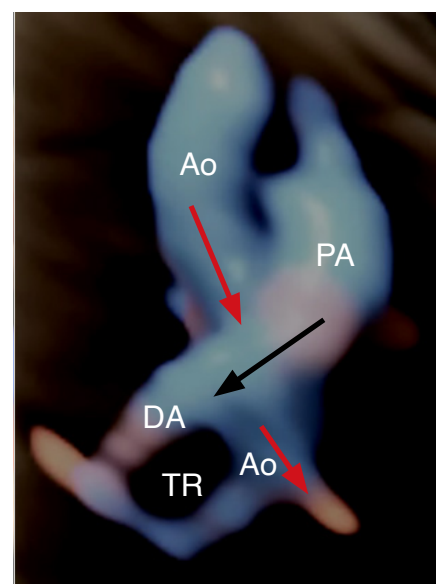

C

Fig. 22. Assessment of the three-vessel-trachea view in a fetus at 30 weeks of gestation with right aortic arch and a vascular ring anomaly.

Echocardiography using two-dimensional ultrasonography with color Doppler (A) and three-dimensional ultrasonography with HDlive Flow (B) and HDlive Flow silhouette (C) rendering modes shows a right aortic arch with a left ductus arteriosus (DA) surrounding the trachea (vascular loop). Black and red arrows show the direction of the blood flow. Ao, aorta artery; PA, pulmonary artery; SVC, superior vena cava; TR, trachea.

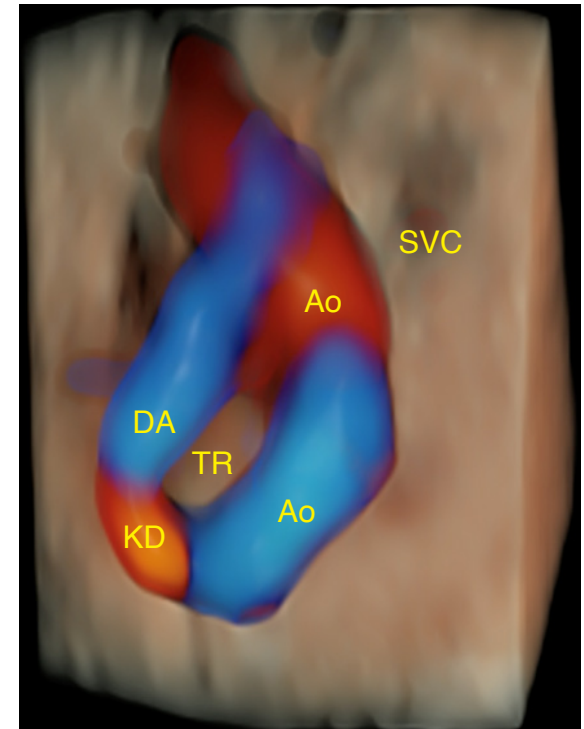

A

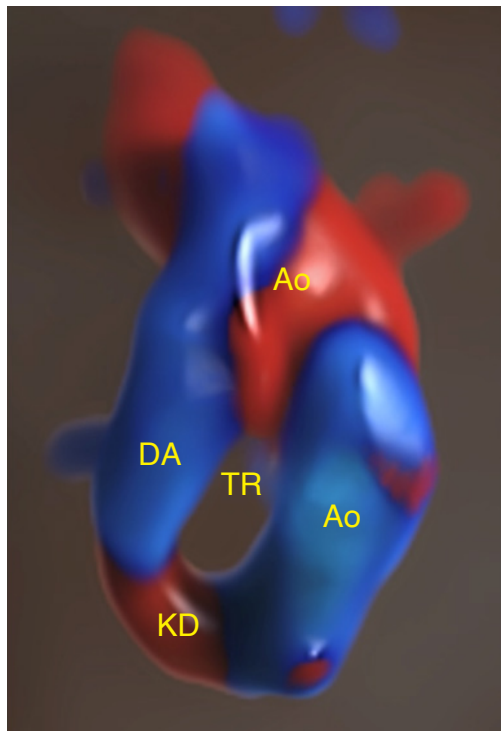

B

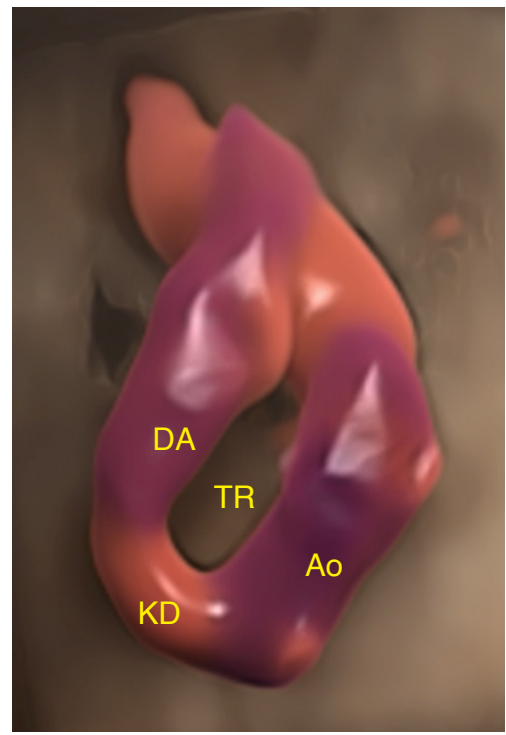

C

Fig. 23. Right aortic arch and Kommerell diverticulum with an aberrant left subclavian artery in a fetus at 22 weeks of gestation.

Three-dimensional ultrasonography images of the three-vessel and trachea view using HDlive Flow (A, B) and HDlive Flow silhouette (C) rendering modes show ductus arteriosus (DA) and right-sided aortic arch ( $A 0)$ on opposite sides of the trachea (TR), forming a U-shaped in appearance complete vascular ring. The vascular loop encompasses the right aortic arch, the left subclavian artery (LSCA) with Kommerell's diverticulum (KD; bulbous configuration of the LSCA) and left posterior ductus. SVC, superior vena cava. 
three-vessel and trachea view $[16,23]$. The HDlive Flow rendering mode of the pulmonary artery, aorta, and ductus arteriosus allows a realistic reconstruction of this vascular ring, known as Kommerell's diverticulum (Figs. 22, 23).

The assessment of the aortic arch branching position abnormalities in fetuses may be difficult using conventional 2D ultrasonography, even with color Doppler. In such cases, the HDlive Flow rendering mode of the aortic arch view can be a valuable tool to detect vessel anomalies (Fig. 24).

\section{Foramen Ovale Aneurysm/Tortuous Ductus Arteriosus}

Although it is often an isolated finding, some studies have demonstrated an association between foramen ovale aneurysm and fetal arrhythmias [24]. Nonetheless, foramen ovale aneurysm is postnatally strongly associated with cryptogenic stroke. HDlive Flow and HDlive Flow silhouette rendering modes provided diagnostic image information to enable this diagnosis (Figs. 25, 26). Indeed, tortuous ductus arteriosus with kinking may be isolated or associated with conotruncal defects, such as PAt with VSD [19]. HDlive Flow enables this assessment with high-quality images of the ductal arch (Figs. 27, 28) [25]. In general, isolated tortuous ductus arteriosus is not clinically significant; however, it may interfere with cardiac hemodynamic procedures in TOF cases.

\section{Anomalous Venous Return}

Anomalous pulmonary venous return (APVR) may be partial (three or fewer pulmonary veins) or total (all four veins). The prenatal diagnosis of APVR remains a tremendous challenge, especially when it is an isolated defect and fewer than three veins are involved. The presence of discrepancy of the ventricles (right ventricle dominance), small left atrium, and difficulties in detecting pulmonary veins into the left atrium are clues for the prenatal diagnosis of total APVR (TAPVR) during ultrasound cardiac screening. Furthermore, an increase in the retro-atrial distance between the left atrium and the descending aorta in the four-chamber view should raise the suspicion of a cardiac form of TAPVR (Fig. 29A, B) [26]. TAPVR requires surgical correction after birth and, in most cases, in the first

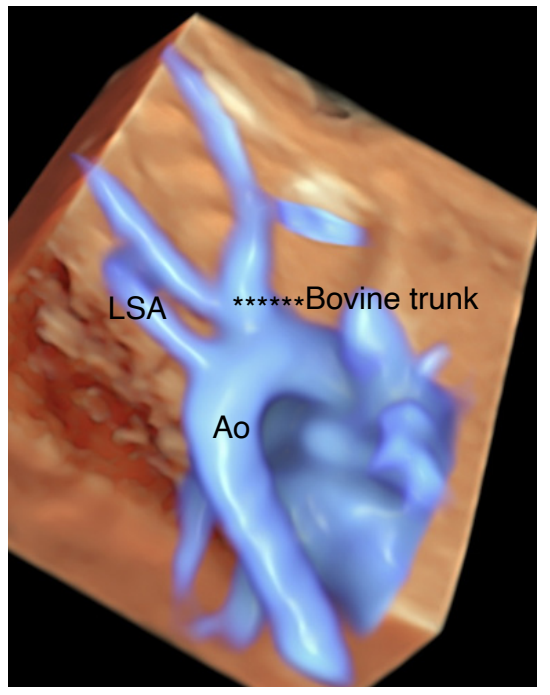

A

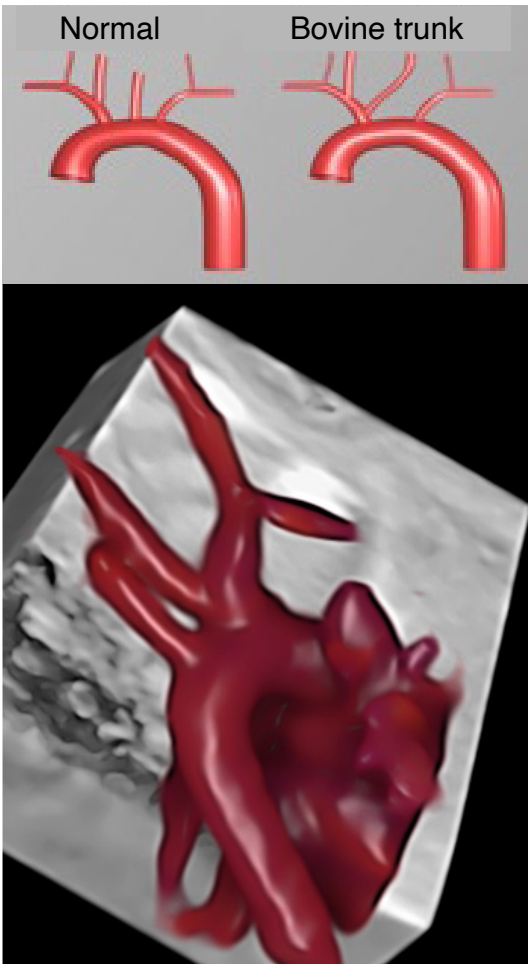

B

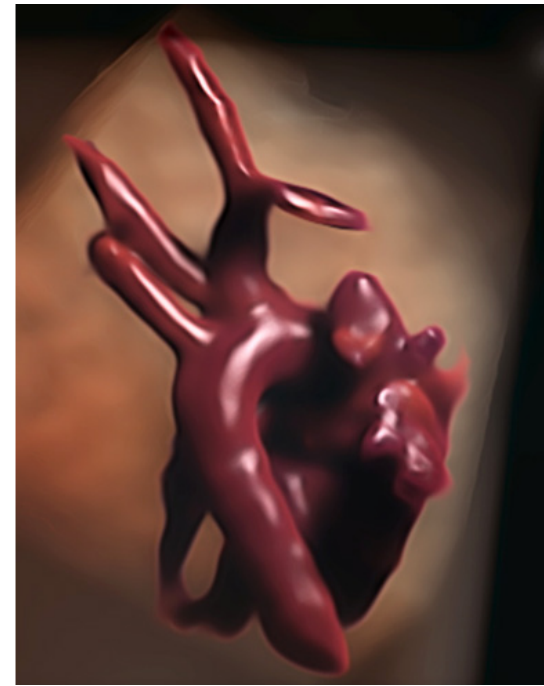

C

Fig. 24. Aortic arch view in a fetus with bovine trunk.

Imaging of the sagittal view of the aortic arch using three-dimensional ultrasonography with HDlive Flow rendering mode $(A-C)$ in a variant of the aortic arch (bovine trunk, asterisks) is shown. The HDlive Flow rendering mode clearly shows the brachiocephalic (innominate) artery shares a common origin with the left common carotid artery. Ao, descending aorta; LSA, left subclavian artery. 


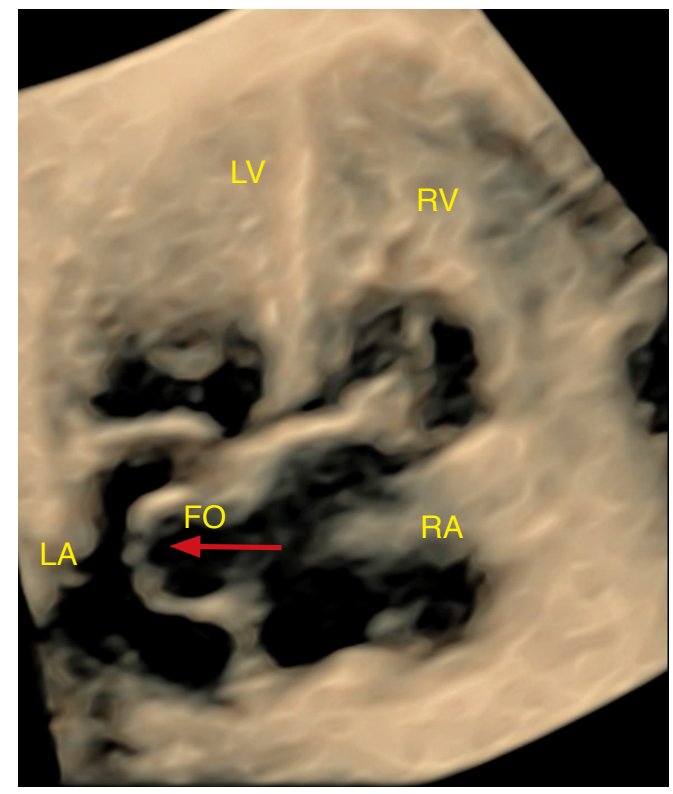

A

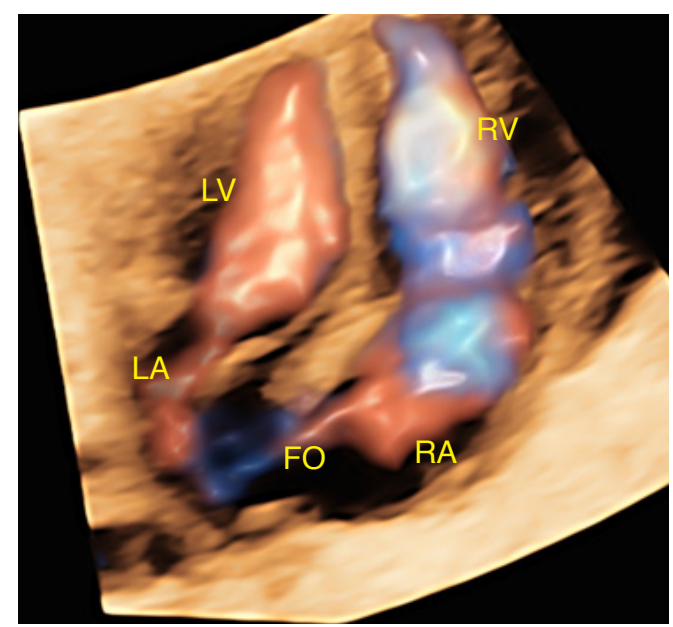

A

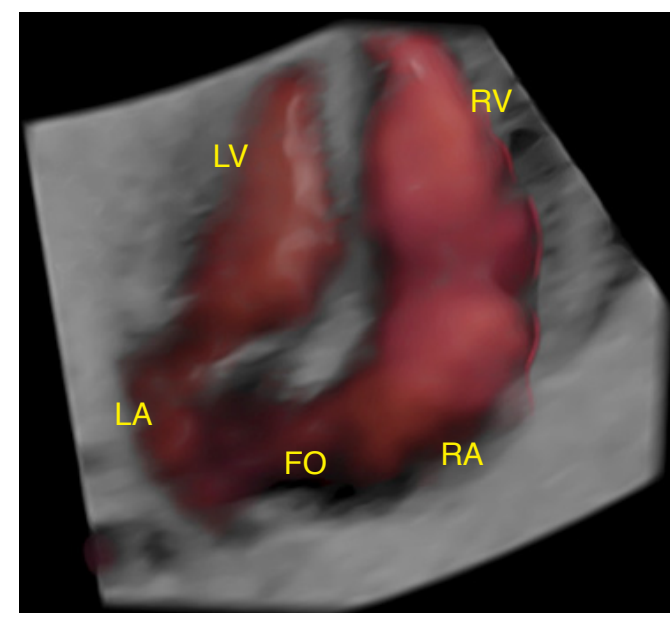

C

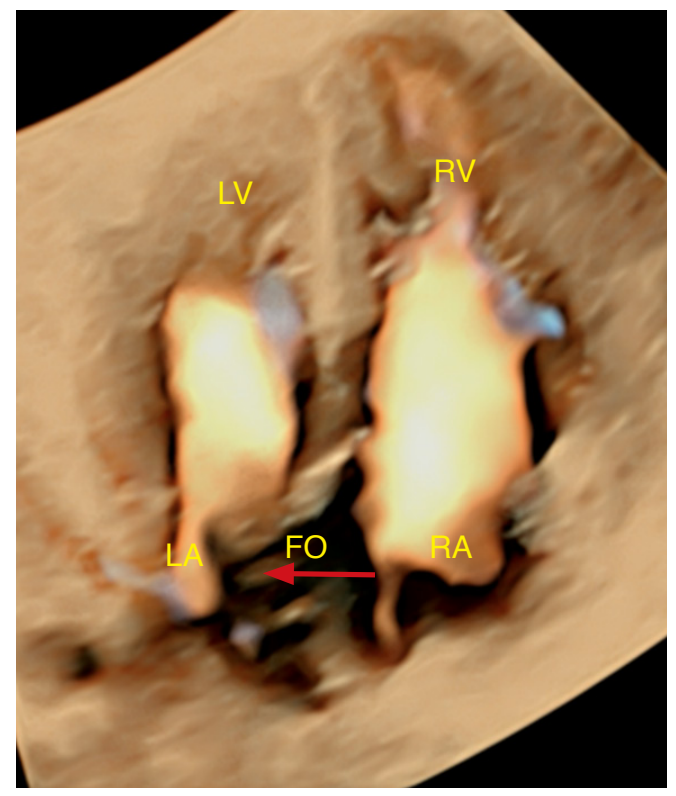

B

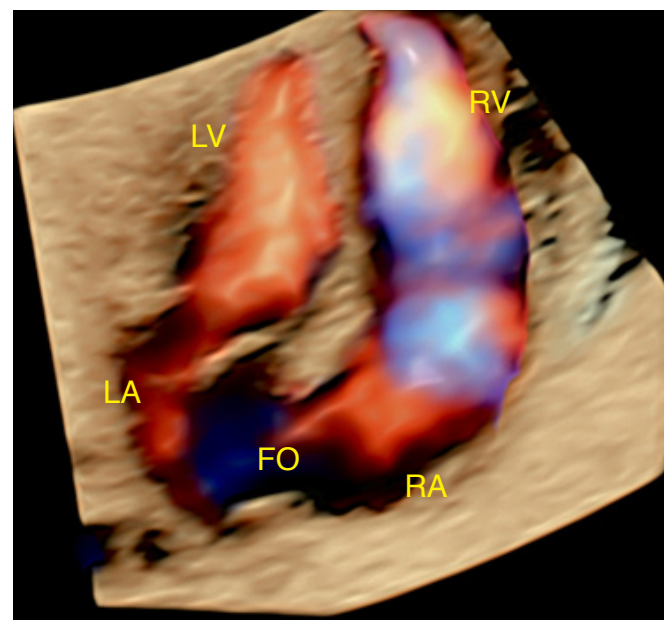

B

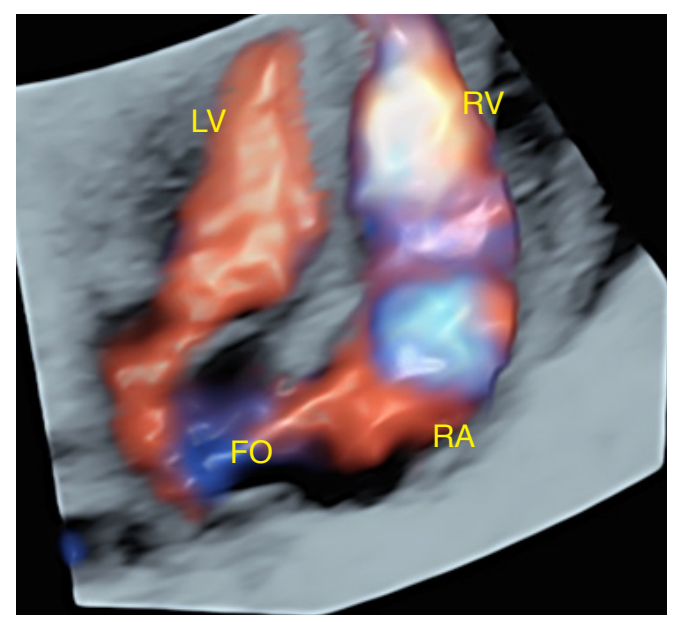

D
Fig. 25. Foramen ovale (FO) aneurysm in a fetus at 37 weeks of gestation.

Imaging of the four-chamber view of the heart using threedimensional ultrasonography with HDlive silhouette (A) and HDlive Flow silhouette (B) rendering modes in a case of FO aneurysm is shown. The red arrow points to the bulging of the atrial septum involving the fossa ovalis region ( $\mathrm{FO}$ aneurysm). FO, foramen ovale; LA, left atrium, LV, left ventricle; $R A$, right atrium; RV, right ventricle.

Fig. 26. Assessment of the blood flow across the foramen ovale (FO) in a case of FO aneurysm.

Imaging of the four-chamber view of the heart using threedimensional ultrasonography with HDlive Flow $(A, B)$ and HDlive Flow silhouette $(C, D)$ rendering modes in a fetus at 37 weeks of gestation with an aneurysm of the $\mathrm{FO}$ is shown. The HDlive Flow rendering allows clear visualization of the blood flow crossing the FO freely from the right atrium (RA) toward the left atrium (LA). $L V$, left ventricle; RV, right ventricle. 


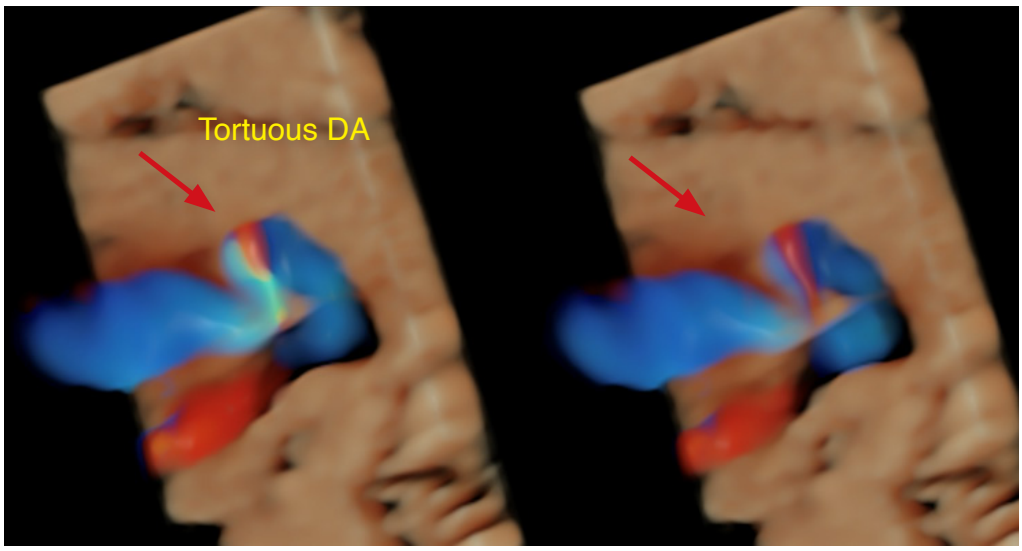

A

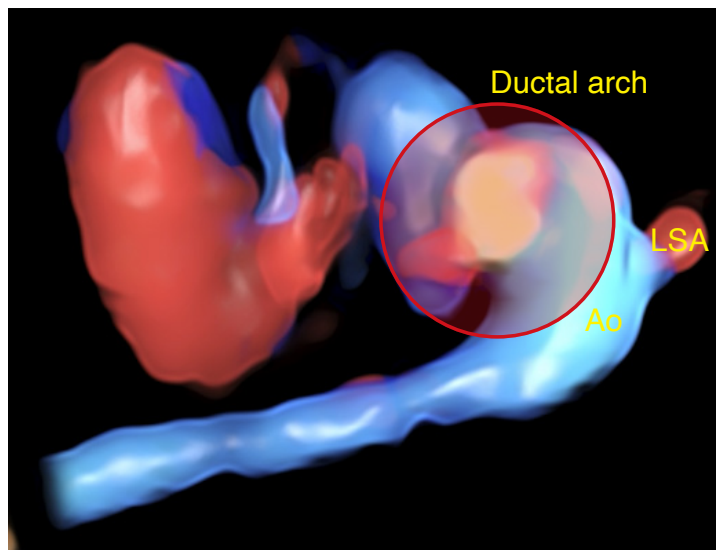

B

Fig. 27. An isolated tortuous ductus arteriosus (DA) in a fetus at 28 weeks of gestation.

Imaging of the three-vessel view (A) and sagittal view of the ductal arch (B) using three-dimensional ultrasonography with HDlive Flow silhouette rendering mode $(A, B)$ in a case of tortuous DA is shown. The red arrow points to the tortuosity of the DA. Ao, aorta; LSA, left subclavian artery.

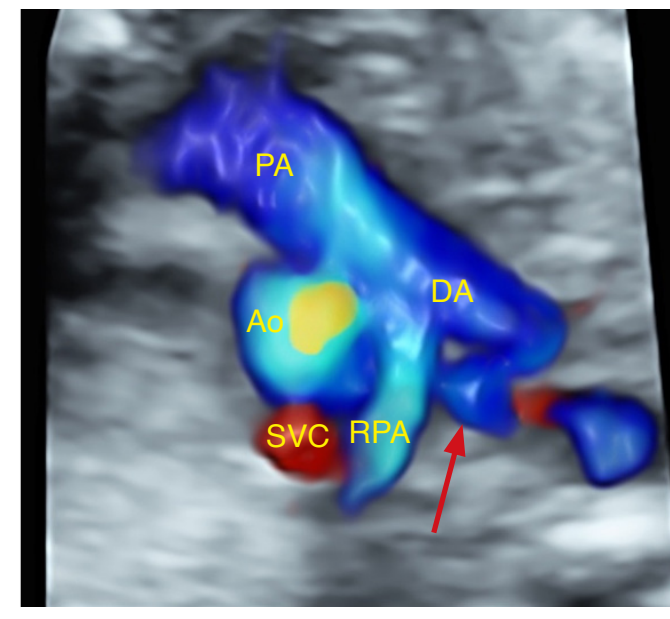

A

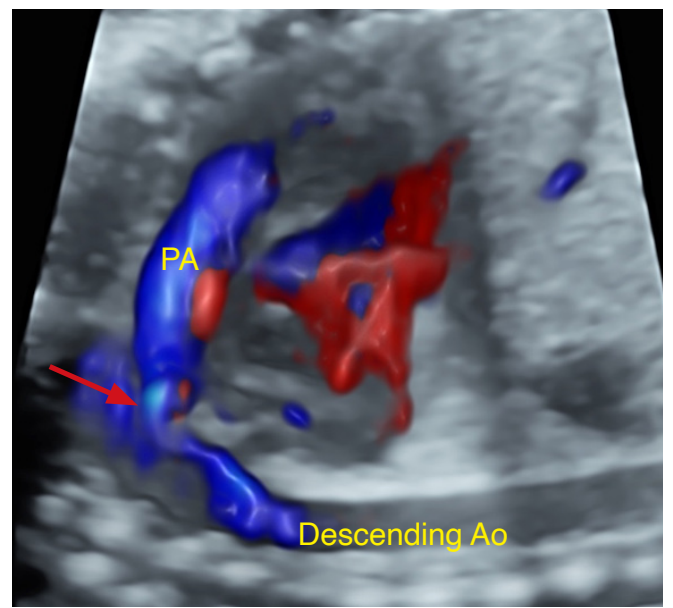

B
Fig. 28. Imaging of the threevessel view $(A)$ and sagittal view of the ductal arch (B) using three-dimensional ultrasonography with HDlive Flow rendering mode in a case of isolated tortuous ductus arteriosus (DA). The red arrows point to the tortuosity of the DA. Ao, aorta; PA, pulmonary artery; RPA, right pulmonary artery; SVC, superior vena cava. weeks of life. In this scenario, the prenatal diagnosis is crucial to reduce the risk of perinatal morbidity and mortality related to this CHD.

Persistent left superior vena cava is the most common variation of the systemic venous. The three-vessel and three-vessel and trachea views enable this diagnosis by showing the presence of a supernumerary vessel (four vessels instead of three) to the left of the pulmonary artery and trachea. In general, the left superior vena cava drains into the coronary sinus and an enlarged coronary sinus can be observed in the four-chamber view (Fig. 29C). Isolated, persistent left superior vena cava has no clinical significance after birth; however, it can be associated with other types of CHD, such as left-heart obstructive diseases.

Advanced technologies such as 3D STIC ultrasonography with the HDlive rendering mode may improve the prenatal diagnosis, enabling the detailed anatomy of the site of the anomalous venous return in case of APVR or other types of CHD, such as persistent left superior vena cava and interruption of the inferior vena cava with azygous continuation $[6,11]$.

\section{Transposition of the Great Arteries}

Transposition of the great arteries (TGA) is a frequent type of cyanotic CHD, in which the aorta arises from the anterior ventricle (morphologically right ventricle) and the pulmonary artery arises from the left ventricle. The four-chamber view is normal in cases of simple TGA, and it is one of the most commonly underdiagnosed types of CHD in utero. However, the outflow tracts are markedly 


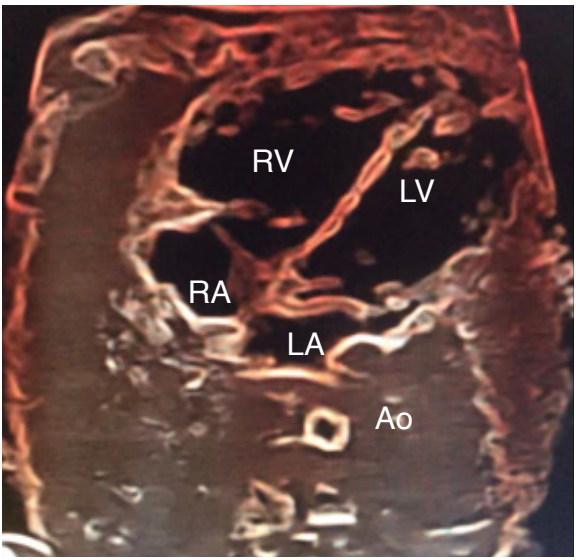

A

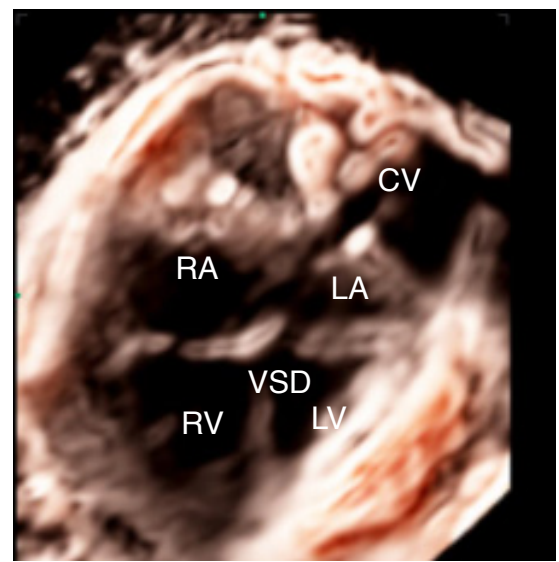

B

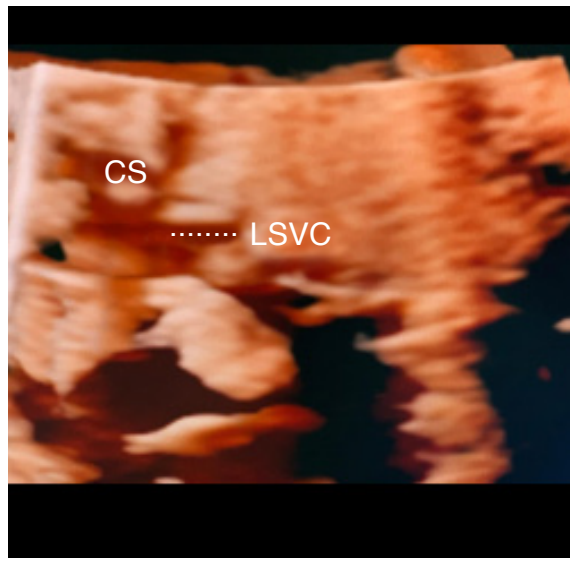

C

Fig. 29. Pulmonary and systemic venous return.

Three-dimensional ultrasonography images of the fetal heart with HDlive silhouette rendering mode show a case with normal pulmonary venous return (A), a case of total anomalous pulmonary venous return and ventricular septal defect (VSD) with a collecting vein (posterior to the left atrium [LA]) (B), and a case of left superior vena cava (LSVC) that drains into the coronary sinus (CS) (C). Ao, aorta; CV, collecting vein (collecting chamber); LV, left ventricle; RA, right atrium; RV, right ventricle.

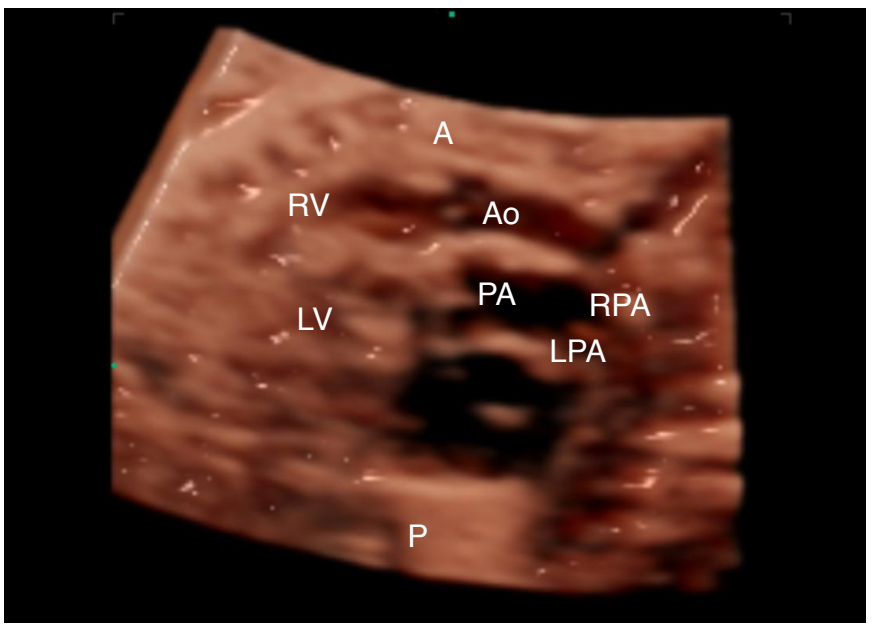

Fig. 30. The outflow tract view in a case of transposition of the great arteries using three-dimensional ultrasonography with HDlive silhouette rendering mode. Note that the great arteries are in a parallel relationship (anterior, aorta; posterior, pulmonary artery). $A$, anterior; Ao, aorta; LPA, left pulmonary artery; LV, left ventricle; $\mathrm{P}$, posterior; PA, pulmonary artery; RPA, right pulmonary artery; RV, right ventricle.

abnormal, since the aorta and pulmonary artery run in parallel and do not cross over each other (Fig. 30). After birth, patients with TGA usually undergo a cardiac intervention during the neonatal period, and the prenatal diagnosis of TGA is crucial [27].

The use of 3D/4D STIC with the HDlive rendering mode may improve the prenatal diagnosis of conotruncal anomalies such as simple TGA, providing a detailed reconstruction of the outflow tracts from a 3D fetal cardiac volume acquired from a standard fourchamber view $[9,11]$.

\section{Conclusion}

A gallery of high-quality images of CHD prenatal diagnoses using the 3D ultrasound STIC in the HDlive Flow and HDlive Flow silhouette rendering modes is presented. This technology provides realistic images of the fetus and its blood vessels, permitting a detailed study of the cardiac anatomy. HDlive can provide an anatomically realistic depiction of normal and abnormal fetal hearts, and it is used to improve the diagnosis of fetal cardiac malformations. Nonetheless, the requirement for an advanced 3D ultrasound apparatus and appropriate operator training are limitations of this new technology in routine clinical practice.

ORCID: André Souza Malho: https://orcid.org/0000-0002-4937-0470; Nathalie Jeanne Bravo-Valenzuela: https://orcid.org/0000-0003-1491-4877; Renato Ximenes: https://orcid.org/0000-0001-7341-6101; Alberto Borges Peixoto: https://orcid.org/00000002-1655-3609; Edward Araujo Júnior: https://orcid.org/0000-0002-6145-2532

\section{Author Contributions}

Conceptualization: Malho AS, Ximenes R. Data analysis or interpretation: Bravo-Valenzuela NJ, Peixoto $A B$, Araujo Júnior $E$. Drafting of the manuscript: Malho AS, Bravo-Valenzuela NJ, Peixoto $A B$, Araujo Júnior $E$. Critical revision of the manuscript: Ximenes $R$, Araujo Júnior $E$. Approval of the final version of the manuscript: all authors. 


\section{Conflict of Interest}

No potential conflict of interest relevant to this article was reported.

\section{References}

1. World Health Organization. Congenital anomalies [Internet]. Geneva: World Health Organization, 2021 [cited 2021 May 24]. Available from: https://www.who.int/teams/maternal-newbornchild-adolescent-health-and-ageing/newborn-health/congenitalanomalies.

2. Hoffman J. The global burden of congenital heart disease. Cardiovasc J Afr 2013;24:141-145.

3. International Society of Ultrasound in Obstetrics and Gynecology; Carvalho JS, Allan LD, Chaoui R, Copel JA, DeVore GR, et al. ISUOG Practice Guidelines (updated): sonographic screening examination of the fetal heart. Ultrasound Obstet Gynecol 2013;41:348-359.

4. Donofrio MT, Moon-Grady AJ, Hornberger LK, Copel JA, Sklansky MS, Abuhamad A, et al. Diagnosis and treatment of fetal cardiac disease: a scientific statement from the American Heart Association. Circulation 2014;129:2183-2242.

5. Chaoui R, Abuhamad A, Martins J, Heling KS. Recent development in three and four dimension fetal echocardiography. Fetal Diagn Ther 2020;47:345-353.

6. Hata T, Koyanagi A, Yamanishi T, Bouno S, Takayoshi R, Nakai Y, et al. Three-dimensional fetal echocardiographic assessment of persistent left superior vena cava with absent right superior vena cava. Donald School J Ultrasound Obstet Gynecol 2020;14:346348.

7. Araujo Junior E, Tonni G, Bravo-Valenzuela NJ, Da Silva Costa $F$, Meagher S. Assessment of fetal congenital heart diseases by 4-dimensional ultrasound using spatiotemporal image correlation: pictorial review. Ultrasound Q 2018;34:11-17.

8. Carrilho MC, Rolo LC, Tonni G, Araujo Junior E. Assessment of the quality of fetal heart standard views using the FAST, STAR, and FINE four-dimensional ultrasound techniques in the screening of congenital heart diseases. Echocardiography 2020;37:114-123.

9. Araujo Junior E, Nardozza LM, Moron AF. Three-dimensional ultrasound STIC-HDlive rendering: new technique to assessing of fetal heart. Rev Bras Cir Cardiovasc 2013;28:v-vii.

10. Hata T, Mashima M, Ito M, Uketa E, Mori N, Ishimura M. Threedimensional HDlive rendering images of the fetal heart. Ultrasound Med Biol 2013;39:1513-1517.

11. Ito $M$, AboEllail MA, Yamamoto $K$, Kanenishi $K$, Tanaka H, Masaoka $\mathrm{H}$, et al. HDlive Flow silhouette mode and spatiotemporal image correlation for diagnosing congenital heart disease. Ultrasound Obstet Gynecol 2017;50:411-415.

12. Hata T, AboEllail MA, Sajapala S, Ishimura M, Masaoka H. HDlive silhouette mode with spatiotemporal image correlation for assessment of the fetal heart. J Ultrasound Med 2016;35:14891495.

13. Hata T, Ito M, Nitta E, Pooh R, Sasahara J, Inamura N. HDlive Flow silhouette mode for diagnosis of ectopia cordis with a left ventricular diverticulum at 15 weeks' gestation. J Ultrasound Med 2018;37:2465-2467.

14. Hata T, Hanaoka U, Kanenishi K. HDlive Flow silhouette mode for fetal heart. Donald School J Ultrasound Obstet Gynecol 2019;13:10-22.

15. Hata T, Koyanagi A, Yamanishi T, Bouno S, Takayoshi R, Miyagi Y, et al. Success rate of five fetal cardiac views using HDlive Flow with spatiotemporal image correlation at 18-21 and 28-31 weeks of gestation. J Perinat Med 2020;48:384-388.

16. Bravo-Valenzuela NJ, Peixoto AB, Araujo Junior E. Prenatal diagnosis of congenital heart disease: a review of current knowledge. Indian Heart J 2018;70:150-164.

17. Gottschalk I, Jehle C, Herberg U, Breuer J, Brockmeier K, Bennink $\mathrm{G}$, et al. Prenatal diagnosis of absent pulmonary valve syndrome from first trimester onwards: novel insights into pathophysiology, associated conditions and outcome. Ultrasound Obstet Gynecol 2017;49:637-642.

18. Hata T, Kanenishi K, Mori N, Yazon AO, Hanaoka U, Tanaka H. Fourdimensional color Doppler reconstruction of the fetal heart with glass-body rendering mode. Am J Cardiol 2014;114:1603-1606.

19. Lopes LM, Bezerra RF, da Silva JP, da Fonseca da Silva L. Critical Ebstein's anomaly with circular shunt: from successful fetal therapy with non-steroidal anti-inflammatory drugs to biventricular repair using Da Silva cone technique. Cardiol Young 2021;31:1039-1042.

20. AboEllail MA, Kanenishi K, Tenkumo C, Kawanishi K, Kaji T, Hata T. Diagnosis of truncus arteriosus in first trimester of pregnancy using transvaginal four-dimensional color Doppler ultrasound. Ultrasound Obstet Gynecol 2015;45:759-760.

21. Traisrisilp K, Tongprasert F, Srisupundit K, Luewan S, Sukpan K, Tongsong T. Prenatal differentiation between truncus arteriosus (Types II and III) and pulmonary atresia with ventricular septal defect. Ultrasound Obstet Gynecol 2015;46:564-570.

22. Lakshmy SR, Jain B, Rose N. Role of HDLive in imaging the fetal heart. J Ultrasound Med 2017;36:1267-1278.

23. AboEllail MA, Kanenishi $K$, Tenkumo C, Mori N, Katayama T, Koyano $\mathrm{K}$, et al. Four-dimensional power Doppler sonography with the HDlive silhouette mode in antenatal diagnosis of a right aortic arch with an aberrant left subclavian artery. J Ultrasound Med 2016;35:661-663.

24. Bozkaya VO, Oskovi-Kaplan ZA, Engin-Ustun Y. Atrial septal aneurysm in pregnancy: echocardiography and obstetric outcomes. J Perinat Med 2020;48:369-375.

25. Karmegaraj B, Rajeshkannan R, Kappanayil M, Vaidyanathan B. Fetal descending aortic tortuosity with ductal aneurysm. Ultrasound Obstet Gynecol 2019;54:142-144. 
26. Ganesan S, Brook MM, Silverman NH, Moon-Grady AJ. Prenatal findings in total anomalous pulmonary venous return: a diagnostic road map starts with obstetric screening views. J Ultrasound Med 2014;33:1193-1207.
27. Bravo-Valenzuela NJ, Peixoto AB, Araujo Junior E. Prenatal diagnosis of transposition of the great arteries: an updated review. Ultrasonography 2020;39:331-339. 